This is the final peer-reviewed accepted manuscript of:

Giovanni Castellazzi, Antonio Maria D’Altri, Stefano de Miranda, Francesco Ubertini, An innovative numerical modeling strategy for the structural analysis of historical monumental buildings, Engineering Structures, Volume 132, 2017, Pages 229-248, ISSN 0141-0296

The final published version is available online at:

https://doi.org/10.1016/j.engstruct.2016.11.032

Rights / License:

The terms and conditions for the reuse of this version of the manuscript are specified in the publishing policy. For all terms of use and more information see the publisher's website.

This item was downloaded from IRIS Università di Bologna (https://cris.unibo.it/)

When citing, please refer to the published version. 


\title{
An innovative numerical modeling strategy for the structural analysis of historical monumental buildings
}

\author{
Giovanni Castellazzi ${ }^{1 *}$, Antonio Maria D’Altri ${ }^{1}$, Stefano de Miranda ${ }^{1}$, Francesco Ubertini ${ }^{1}$ \\ ${ }^{1}$ Department of Civil, Chemical, Environmental, and Materials Engineering (DICAM), University of Bologna, V.le \\ Risorgimento 2, Bologna, Italy
}

\begin{abstract}
In this paper, an innovative numerical modeling strategy for the structural analysis of historical monumental buildings is presented. The strategy is based on a procedure that enables the semiautomatic transformation of a three-dimensional points cloud surveyed through terrestrial laser scanner or closed range photogrammetry into a three-dimensional finite element mesh, as well as its mechanical characterization. Therefore, an increase of the level of automation in the mesh generation process is attained and a large reduction in the required time in comparison with traditional modeling procedures is achieved. In order to validate the new strategy, an application to the case study of the San Felice sul Panaro (Italy) fortress is carried out. The reliability of the proposed model is assessed through a comparison between the results of structural analyses and the crack pattern experienced by the structure during the Emilia earthquake (2012). Moreover, the vulnerability assessment of the main tower of the fortress is performed through simplified pushover analyses conducted on the generated mesh.
\end{abstract}

Keywords: Mesh generation, Historical buildings, Finite element method, Structural analysis, Points cloud, Laser scanning, Seismic vulnerability assessment

\section{Introduction}

The conservation of historical buildings often exploits structural analyses as a way to better understand the authentic structural and constructive features and to estimate the safety conditions of the building. Typically, structural analyses are a fundamental tool to catch the weaknesses of the structure under vertical or seismic loads, which is necessary to understand the cost and magnitude of the safety interventions required $[1,2,3,4]$.

Historical structures are characterized by an enormous complexity in terms of geometry, materials properties, loads and boundary conditions, hence, in most cases, the Finite Element Method (FEM) has been used in order to model these features. From the first significant contributions $[5,6,7]$, related to famous examples of architectural heritage, the FE analysis of historical buildings has been considerably developed. An interesting review of classical and advanced approaches

\footnotetext{
*corresponding author: giovanni.castellazzi@unibo.it
} 
for the structural analysis of masonry historical constructions can be found in [8]. A contribution to the issue of FE modeling and analysis of architectural heritage through the discussion of an illustrative case study of an Italian medieval castle has been presented in [9], where a three-dimensional numerical model of the castle has been used to identify the main sources of damage and assess the effectiveness of the restoration works. Another significant contribution is the structural and seismic assessment of the 19th-century Petruzzelli theater in Bari (Italy), presented in [10]. The numerical model of Brunelleschi's Dome of Santa Maria del Fiore, with an ad hoc nonlinear procedure to replicate the mechanical behavior of masonry, has been reported in [11]: the obtained results allowed to assess and discuss both the Dome's internal stress and cracking pattern. In [12], a multidisciplinary approach, with a balanced fusion of historical analysis, precision surveys, experimental inspections and numerical modeling, enabled to spot the damage mechanisms of the French Panthéon. In [13], the seismic assessment of an old masonry tower has been addressed by developing three FE models with different levels of complexity while, in $[14,15]$, the seismic risk assessment of a masonry chimney has been evaluated by using advanced analysis techniques. Moreover, the FEM modeling of the towers of a temple in Cambodia has been presented in [16], whereas a comparative numerical study on a 12th-century masonry tower has been described in [17]. To assess the safety of the tower under seismic loads, the authors employed different numerical analyses such as nonlinear static, limit, and nonlinear full dynamic analyses. Finally, in [18], the results of a wide numerical campaign conducted on the clock tower in Finale Emilia (Italy), collapsed during the main shock of the devastating Emilia earthquake seismic sequence (2012), are collected.

From the above literature overview, it appears that the interest for the numerical modeling of historical buildings increased in the last years and that the FEM can be considered as an effective tool to investigate the structural behavior of this kind of buildings. Notwithstanding this, the numerical modeling of historical monumental buildings is still a challenging task for contemporary civil engineers. One of the main reasons for this is that, due to the complex geometry of such historic structures, the use of traditional simplified structural schemes is inadequate. Thereby, it is unavoidable to resort to a fully three-dimensional modeling that often is performed using the Computer Aided Design (CAD), as is the case in most of the cited studies. In general, CAD based modeling is an expensive and complex process, often manually carried out by the user, which inevitably leads to the introduction of geometric simplifications (Defeaturing) or interpretations.

In order to reduce the time that the user has to spend to reproduce the complex geometry of these structures, a precious support can be supplied by automatic advanced survey techniques such as Terrestrial Laser Scanner (TLS) [19] and terrestrial photogrammetry [20], which can generate three-dimensional detailed points clouds in a rapid way. Although the TLS is still today an expensive survey technique in comparison with closed range photogrammetry systems [21], its usage is showing a high growth coupled with a continuous technological development. In particular, in the field of architectural heritage several TLS and photogrammetric applications have been performed: from simple documentation [22] to monitoring the condition of historical buildings, and also in order to support restoration works or structural checks [23, 24]. An example is reported in [25], where a detailed geometric survey of a Portuguese Castle is conducted by means of the laser scanning technique, allowing for a precise characterization of dimensions and disposition of the masonry blocks used for the FE discretization. Another example is shown in [26], where 
the significant deformation of a Spanish Church has been surveyed by means of TLS: the threedimensional structural model has been created in a CAD environment using the results of the laser scanner survey. Thereby, the current deformation of the church has been directly considered in the structural analyses.

Several studies try to transform three-dimensional points clouds in FE models, but in most cases the output is simple or dramatically simplified. For instance, in [27] a three-dimensional points cloud is used to generate models of the cross sections of historical walls for structural analysis application, while in [28] an example of FE analysis of a historic theater is performed using laser scanning data limited to the inner surfaces of the building. Massive structures, such as masonry bridges can also be investigated by summing the laser scanner survey information to those obtained by ground penetrating radar and as a result generate a fine picture of the external and internal features [29]. Here, the cloud simplification lies on the sampling of some points that are useful to reconstruct the geometry by means of regular shapes. Other interesting contributions are proposed in $[30,31]$, where an attempt to precisely capture the geometry of the building through the automatic reconstruction of its boundary is presented. Moreover, in [32] a point-based voxelization method to automatically transform point cloud data into solid models for computational modeling is developed. The method constructs a Triangular Irregular Network (TIN) mesh by means of a voxel grid bounding the cloud region. The resulting model captures the threedimensionality of the survey, but does not capture the whole structure, since it is designed for the façade only.

One of the most frequent problems when dealing with complex historical buildings is the impossibility to generate "closed surfaces" from the point cloud of the surveyed object. Thereby, it is not possible to directly transform the TIN mesh surfaces into solid geometry and consequently into a FE mesh, as done, for instance, for agricultural objects in [33] and for Michelangelo's David in [34]. In order to solve this lack of numerical tools, recently in [35, 36] the authors developed a procedure that allows the simple and rapid transformation of a three-dimensional point cloud into a FE model. The procedure, called CLOUD2FEM, starts from TLS or photogrammetric surveys of historical monumental buildings and semi-automatically generates FE models.

On the basis of this procedure to generate FE meshes, an innovative numerical modeling strategy for the structural analysis of historical monumental buildings is presented in this paper. The strategy is mainly composed of: (i) a structural breakdown that allows a fine semi-automatic creation of the geometrical domain starting from a TLS or photogrammetric survey; (ii) a structural discretization capable of always guaranteeing the generation of the FE mesh by means of three-dimensional hexahedral elements; and (iii) an easy and effective treatment of the mechanical characterization of the FE mesh and of the connections between adjacent macro-elements. The main innovative feature of the proposed numerical modeling strategy of historical buildings consists mainly in the possibility to intensely exploit TLS and photogrammetric surveys of historical buildings for structural purposes, with a large reduction in required time in comparison with CADbased modeling procedures and with an increase of the level of automation in the mesh generation process. In addition, this novel approach resolves the auto-meshing failure issues which often characterize historical structures complex geometries. Moreover, a detailed materials characterization of the generated models is achievable, as well as the possibility to iteratively sub-structure the numerical model. Finally, the simplified management of adjacent macro-elements connections 
is useful to assess their structural interaction.

In order to show the potential and the reliability of the proposed strategy, the application to the case study of the San Felice sul Panaro (Italy) fortress is presented. This application aims at validating the numerical strategy from the structural point of view according to the requirements of the Italian guidelines on cultural heritage [37] (\$2.5). Several linear and nonlinear static analyses under vertical and horizontal loads have been performed. Much attention has been paid to the modeling of the connections between fortress adjacent macro-elements. A comparison between structural analyses results and the crack pattern experienced by the structure during the Emilia earthquake (2012) has been carried out. Moreover, the vulnerability assessment of the main tower of the fortress is performed through simplified pushover analyses conducted on the generated mesh.

The paper is organized as follows. Section 2 presents the new numerical modeling strategy for structural analysis of historical monumental buildings. Section 3 presents the case study features. Section 4 summarizes the results of the structural analyses, validating the FE model through a comparison between the numerical results and the crack pattern affecting the structure due to the Emilia earthquake and showing the vulnerability assessment of the main tower of the fortress. Some concluding remarks end the paper (Section 5).

\section{Numerical modeling strategy}

The goal of the proposed strategy is to offer a simple and effective tool for scientists and practitioners to be able to build FE models of complex large-scale structures, such as monumental buildings, with a minimal time investment. To achieve this goal the strategy innovations are twofold: (i) simple and effective reduction of complex laser scanner and photogrammetric point clouds to FE models; (ii) simple and easy manipulation of the FE models into any commercial or custom FE code.

\subsection{Structural breakdown: divide and conquer algorithm}

As anticipated in Section 1, monumental buildings cannot be, in general, represented by means of simplified structural models, since they lack of geometrical regularity. Thereby, their subdivision into macro FE is not possible or ends to be not effective. In this case, the usage of fully three-dimensional FE models is preferable. However, this operation needs, as previously mentioned, the fine definition of the geometrical domain. Therefore, in the spirit of the divide and conquer algorithm, we propose to breakdown the structure geometry through the application of a systematic procedure that recursively performs the breakdown of the three-dimensional domain into smaller bi-dimensional sub-domains. Masonry structures are made by alternate layers of mortar joints and bricks, and bricks layers create, in general, horizontal planes. Thereby, for such structures the vertical $(z)$ direction is a sort of "principal direction" and this suggests that the subdivision of the three-dimensional structural domain into bi-dimensional ones can be performed by slicing the structure perpendicularly to the $z$ direction. Such slicing operation is at the basis of the CLOUD2FEM procedure [35], which conceives the point cloud as a stacking of points sections, transforming a three-dimensional problem in several bi-dimensional ones, which are easier to be managed. The points cloud is subdivided by subsequent section planes which are characterized 
by a constant incrementation of the coordinate plane. The increment is chosen according to the complexity of the building along the slicing direction. All of the points $P$ included between two subsequent section planes can be projected to the closer ones:

$$
\forall P(x, y, z) \in\left[\bar{z}_{i}-\frac{\Delta z}{2}, \bar{z}_{i}+\frac{\Delta z}{2}\right] \longmapsto \bar{P}\left(x, y, \bar{z}_{i}\right),
$$

where $\bar{z}_{i}$ is the midplane of the $i$-th slice and $\Delta z$ is the slicing step.

A boundary polygon that encloses the points of each slice can be computed using a concave hull algorithm. The results of this operation are, in the simpler case, two polygons, the first made by connecting the points that belong to the external points cloud and the second made by connecting the points that belong to the internal points cloud. By subtracting the second from the first, it is possible to obtain a filled region for each slice of the building that describes the entire structure. The outcome describes the structure by means of a sub-set of slices that precisely reproduces the features of the structure at each $\bar{z}_{i}$ coordinate (see Figure 1(a)).
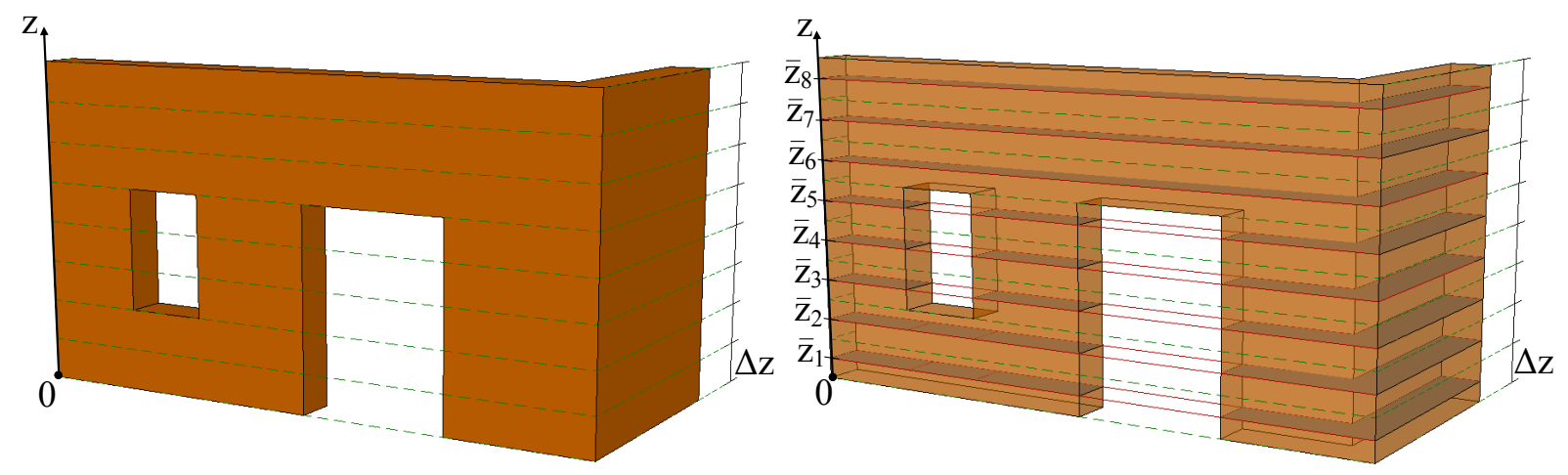

(a) Description of a three-dimensional object by means of slices

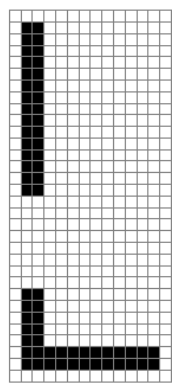

1 st slice

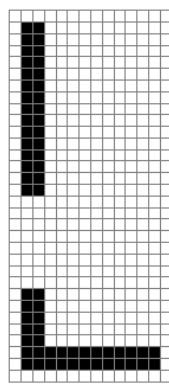

2nd slice

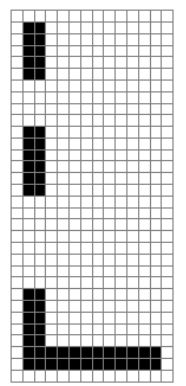

3rd slice

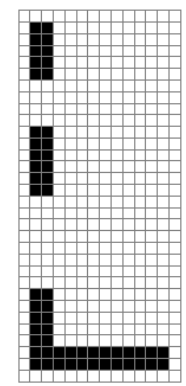

4th slice

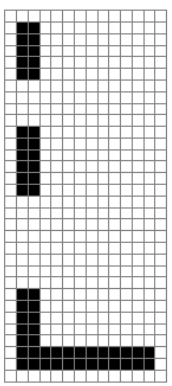

5th slice

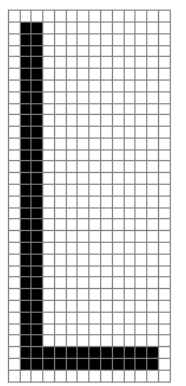

6th slice

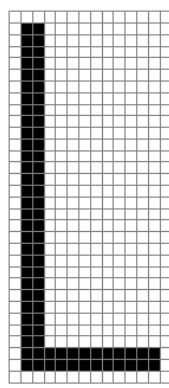

7th slice 8 th slice

(b) Digitalized slices $(N \times M$ pixel matrices $)$

Figure 1: Slicing of the structure and slices digitalization.

\subsection{Structural discretization: guaranteed meshing}

Meshing of complex geometries is an hard task and requires some skills in order to be able to complete the discretization operation. Often, in order to close automatic mesh generation without biasing, small geometry simplifications are needed (Defeaturing). Dealing with monumental 
buildings, the geometrical simplification of the structure is a common and accepted operation, especially for preliminary studies, when the understanding of the structural behavior is crucial.

Therefore, in order to speed up the meshing operation, and to guarantee the automatic mesh generation, we introduce our peculiar discretization. Each slice is idealized as a digital image, composed of picture elements (pixels), with a certain resolution (Figure 1(b)). Since the digitalization is performed on each slice with a fixed space region, they are stackable. This is a major advantage since it guarantees by definition the meshing procedure.

The slices stacking sequence generates the volume elements (voxels). The full reconstruction of the original three-dimensional geometry is obtained by stacking all of the slices: this produces a three-dimensional matrix composed by voxels. The resulting dataset is simple and easy to use with the finite element technique: each voxel is automatically transformed into an eight-node hexahedral finite element. For practical usage this operation could be performed selectively: for instance only on filled parts (certain voxel values). Therefore, the structure is completely discretized as an unique continuum generated by the assembly of eight-node hexahedral elements.

The resulting FE model is characterized by elements of the same dimensions: this aspect introduces an automatic defeaturing of the model that the user can set according to the element dimensions. Moreover, the nodes are evenly distributed over the structure. Of course, this it is not to be considered as a limitation of the method. In fact, the application of octree-based refinement or laplacian smoothing operation can easily improve the geometrical quality of the mesh with little effort [30].

\subsection{Structural modeling: materials and connections characterization}

Once the structural breakdown and the mesh discretization procedure are set by means of defining the parameters $\bar{z}_{i}, \Delta z$ and the pixels resolution, the user is able to build the mesh. If no specifications are made during the aforementioned operations, the resulting mesh will be associated to an unique (default) material identifier. Therefore, material associations can be conducted, as usual, by selecting single or groups of elements. On the other hand, the mechanical characterization of the FE model can be conducted in a very easy way. Indeed, once the digitalization of each slice has been concluded, the material characterization of the FE mesh can be simply conducted on each slice by the user through a material ID assignment before the stacking operation (for instance through the pixel colors in a bi-dimensional environment).

Historical buildings are often composed by several adjacent macro-elements built in different eras. To assess the structural behavior of a building, the accurate modeling of the connections between adjacent macro-elements is fundamental. In general, in dynamic regime, the interaction between deformable regions can be described by means of advanced approaches such as those shown in $[38,39,40,41]$. On the other hand, in this paper the attention is focused on static analyses and then, aiming at obtaining the simplest FE model, we propose to model the connections by simply modifying the material properties of the connection zone. Therefore, connections are simply inserted by manipulating the three-dimensional voxels based matrix, or, equivalently, a layer of three-dimensional FE between adjacent macro-elements. Since monumental historical buildings are characterized by great dimensions, the three-dimensional domains associated to the connections are in most cases negligible in comparison to the global volume. Moreover, masonry buildings are characterized in the majority of cases by orthogonal walls, resulting in a mesh grid 
which is well oriented and with evenly spaced nodes. Therefore, the identification and selection of the layer of elements associated to the connection is very easy. However, in the uncommon case of diagonal connections, or when walls are not parallel to the digitalization directions, a local re-meshing to model the connections can be used.

In general, the mechanical behavior of connections varies from a compression stress state (closing of connections) to a tensile stress state (opening of connections). Plausibly, in compression stress state the connections tend to have the same mechanical behavior of the surrounding material. On the other hand, in a tensile stress state the connections' behavior is largely affected by the quality of the masonry toothing between adjacent macro-elements. In the following, we distinguish three connection levels: high quality connections (Fully connected), absence of toothing between macro-elements (Not connected), and an intermediate level (Partially connected). Assuming, for simplicity, that the connections have an isotropic behavior, the simplified mechanical characterization of the three connection levels is sketched in Table 1.

Table 1: Connections simplified mechanical characterization: $E_{c o n}$ and $G_{c o n}$ are the Young's modulus and shear modulus of the connection, respectively, while $E_{m}$ and $G_{m}$ are the Young's modulus and shear modulus of the masonry, respectively.

\begin{tabular}{|c|c|c|}
\hline \multicolumn{3}{|c|}{ Closing of connection } \\
\hline$E_{c o n}$ & $=E_{m}$ & \\
\hline$G_{c o n}$ & $\begin{array}{l}=G_{m} \\
=G_{m} / \gamma_{G c} \text { with } \gamma_{G c} \geq 1\end{array}$ & $\begin{array}{l}\text { Fully connected } \\
\text { Partially and Not connected }\end{array}$ \\
\hline \multicolumn{3}{|c|}{ Opening of connection } \\
\hline$E_{c o n}$ & $\begin{array}{l}=E_{m} \\
=E_{m} / \gamma_{E t} \text { with } \gamma_{E t} \geq 1 \\
\ll E_{m}\end{array}$ & $\begin{array}{l}\text { Fully connected } \\
\text { Partially connected } \\
\text { Not connected }\end{array}$ \\
\hline$G_{c o n}$ & $\begin{array}{l}=G_{m} \\
=G_{m} / \gamma_{G t} \text { with } \gamma_{G t} \geq 1 \\
\ll G_{m}\end{array}$ & $\begin{array}{l}\text { Fully connected } \\
\text { Partially connected } \\
\text { Not connected }\end{array}$ \\
\hline
\end{tabular}

If a finer modeling is required, the connections can be assumed to have an orthotropic behavior and the mechanical properties can be set, for instance, through a tuning on experimental data [42].

\section{The case study: The San Felice sul Panaro fortress}

The San Felice sul Panaro fortress is a monumental historical building located near the city of Modena, in San Felice sul Panaro (Italy). The monument (Figure 2) is a typical example of fortified medieval architecture, composed by a massive quadrilateral plan with an inner yard and 


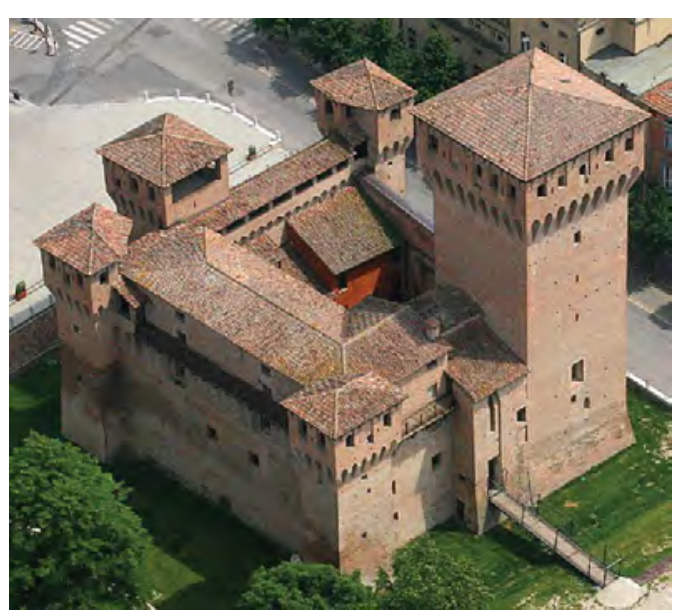

(a) The fortress

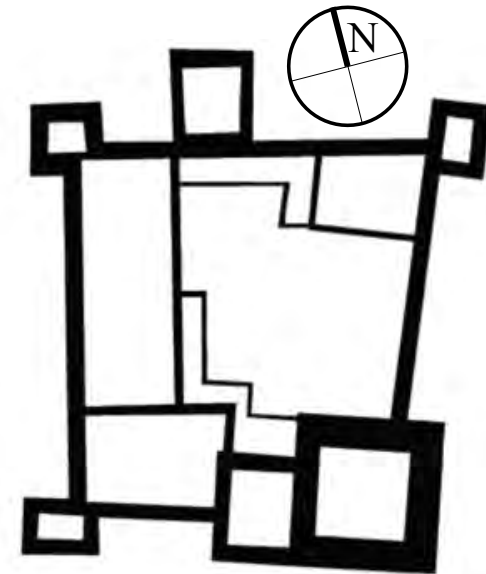

(b) Schematic plan

Figure 2: San Felice sul Panaro fortress.

five towers (Figure 2(b)). Four towers are located at the corners, while another one is placed on the north fortress façade. The S-E tower is called "Mastio" because of its dominant dimensions compared to the rest of the building (Figure 2(a)).

The San Felice sul Panaro fortress exhibits a complex historical evolution during the centuries. A precise and detailed historical reconstruction of the evolution phases of the fortress is reported in $[43,44]$. The main construction stages of the fortress historical evolution can be summarized as follows:

- lower parts of Mastio and North Tower and perimetral walls: XIV century;

- upper parts of Mastio and North Tower and other towers: XV century;

- roofings and internal structures: from XVI to XVIII centuries;

- modern interventions (such as concrete curbs on minor towers and Mastio's trunk reinforcement): XX century.

\subsection{Emilia earthquake damage}

In 2012, the San Felice sul Panaro fortress was hit by the Emilia earthquake with two magnitude peaks of $M_{W}=5.86$ (May 20th) and $M_{W}=5.66$ (May 29th) [45]. The epicenters of the first (May 20th) and the second (May 29th) main shocks were located at about ten and five kilometers far from the fortress, respectively. After such a seismic sequence, the collapse of the four minor towers' roofs was observed and cracks of different relevance appeared on all the fortress structural elements extensively, see Figure 3. In [46], an accurate description of the monument damage mechanisms is reported.

After first-aid structural interventions aimed to preserve the building were performed, the municipality of San Felice sul Panaro did a fine survey of all the external and internal surfaces of the damaged building by using TLS (Figure 4) in order to acquire a snapshot of the post-earthquake condition of the structure and to measure its complex geometry. The raw points cloud of the whole 


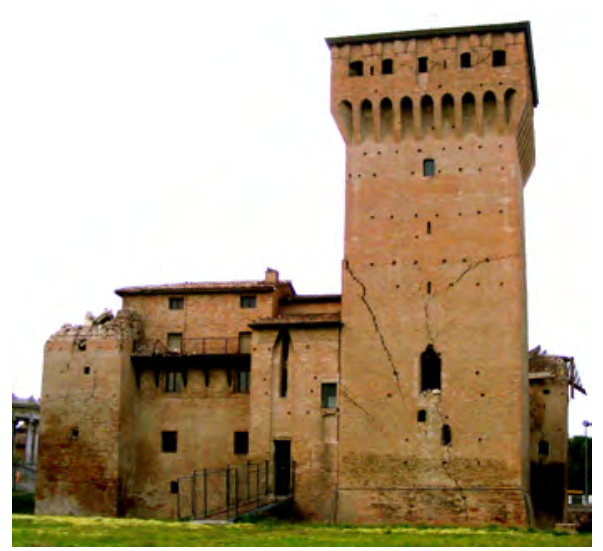

(a) South front

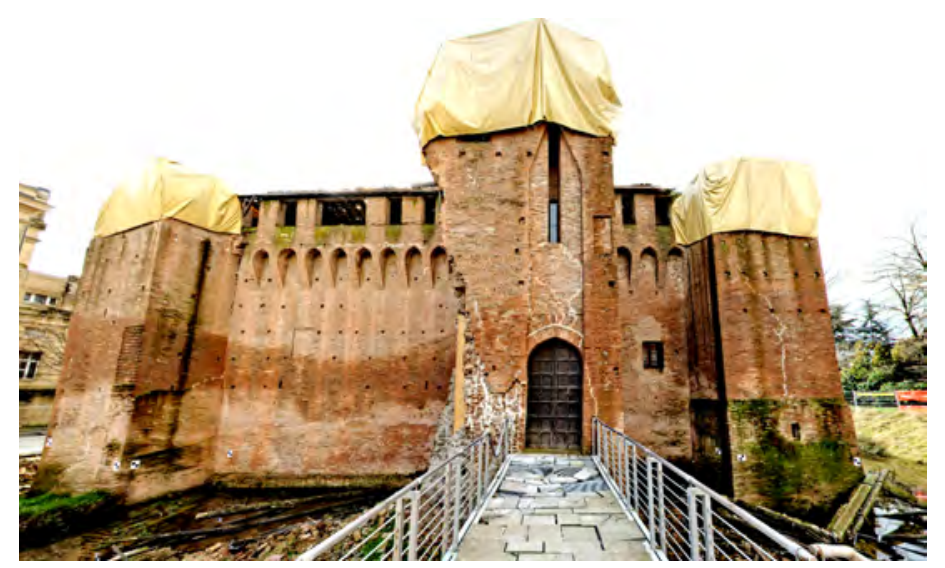

(b) North front

Figure 3: San Felice sul Panaro fortress after Emilia earthquake (2012).

building (composed by over 40 millions of points) as well as the surrounding buildings is shown in Figure 4(a), while the TIN mesh reconstruction is shown in Figure 4(b).

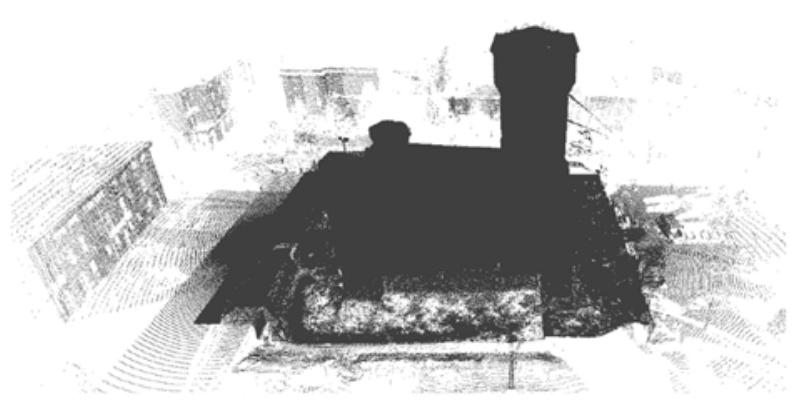

(a) Points cloud

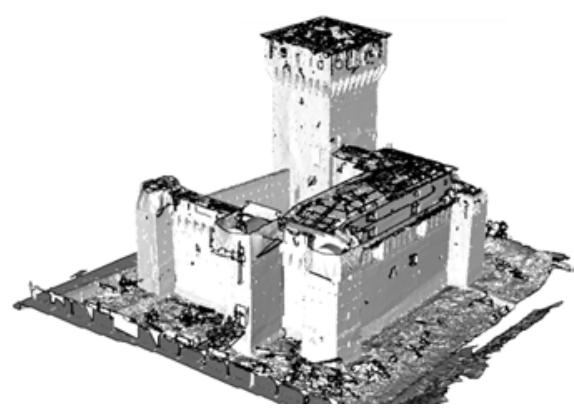

(b) TIN mesh

Figure 4: TLS survey

\section{Strategy validation}

In order to extensively test the proposed modeling strategy and to show its capabilities and reliability, an application to the San Felice sul Panaro fortress has been carried out. After a semiautomatic generation of the fortress FE model, both linear and nonlinear analyses have been performed. The goal of these analyses is twofold: (i) to validate the numerical model of the structure, as requested by the Italian guidelines [37] by comparing the results of the structural analyses and the crack pattern caused by the Emilia earthquake (2012) and (ii) to assess the seismic vulnerability of the main tower of the fortress through a simplified nonlinear method. All the structural analyses have been performed using the commercial FE software Abaqus [47]. 


\subsection{From the points cloud to the FE mesh of the fortress}

From the TLS points cloud, 121 digital slices have been stacked: a vertical gap $\Delta z=25 \mathrm{~cm}$ coupled with a bi-dimensional resolution in the horizontal plane of $25 \mathrm{~cm} \times 25 \mathrm{~cm}$ has been chosen, as suggested in [48]. Indeed, in [48] the authors carried out a comparison in terms of natural frequencies between different mesh sizes of the main tower of the fortress. Furthermore, the effectiveness of the meshing approach has been also investigated in [35] through a comparison with a very detailed CAD-based model. As a result, the resolution $25 \times 25 \times 25 \mathrm{~cm}$ was found to be the best compromise between results accuracy and computational effort. In fact, although this mesh dimension does not accurately reproduce every small architectural detail, it guarantees a good accuracy in terms of global structural response. Therefore, such a resolution has been adopted in this paper since we are interested in analyzing the global behavior of the structure. Figure 5 shows some examples of digitalized slices of the fortress and a sketch of their stacking sequence.

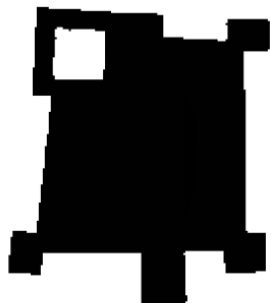

m-th slice

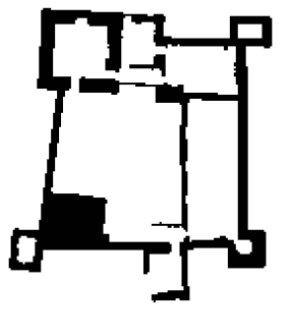

n-th slice

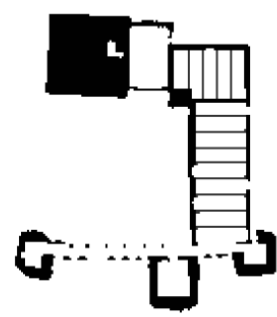

r-th slice

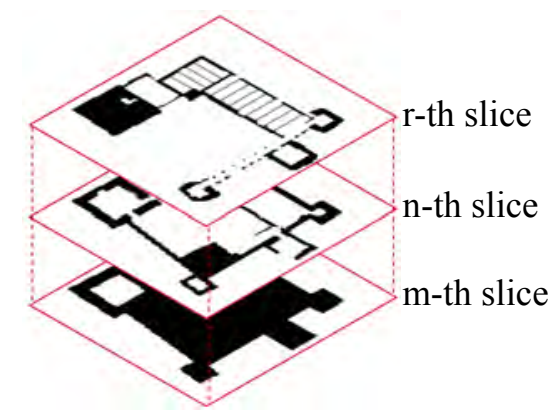

Figure 5: Examples of digitalized slices of the fortress and their stacking.

The resulting mesh, depicted in Figure 6, is characterized by 409,300 hexaedral finite elements (each one $25 \times 25 \times 25 \mathrm{~cm}$ ) and 1,512,444 dofs. Four different materials have been used, whose mechanical properties have been set according to $[49,50,51]$ and are collected in Table 2 . In Figure 6, the Mastio's trunk top part is depicted with a different color because it is composed by reinforced masonry due to the presence of steel tie-rods added in the 90s [44].

Table 2: Materials mechanical properties [49, 50, 51].

\begin{tabular}{ccccc}
\hline ID & Material & Young's modulus $[\mathrm{MPa}]$ & Shear modulus $[\mathrm{MPa}]$ & Density $\left[\mathrm{kg} / \mathrm{m}^{3}\right]$ \\
\hline \hline 1 & Masonry & 1500 & 625 & 1800 \\
2 & Reinf. masonry & 1900 & 792 & 1800 \\
3 & Timber & 8000 & 2918 & 415 \\
4 & Terrain & 935 & 316 & 1200 \\
\hline
\end{tabular}

Modeling the floors and vaults has always been a very significant issue when dealing with numerical models of masonry structures. Following the proposed strategy, floors and vaults are automatically meshed through a jagged representation of the original geometry. Indeed, it is always possible to improve the mesh accuracy using a smoothing method to reduce the faceting, as 
presented in [48]. Nevertheless, in order to assess the global behavior of a historical structure, the geometrical accuracy of the raw mesh can be considered satisfactory even if vaults are present, as in the current case (for instance see the sections in Figure 6). 

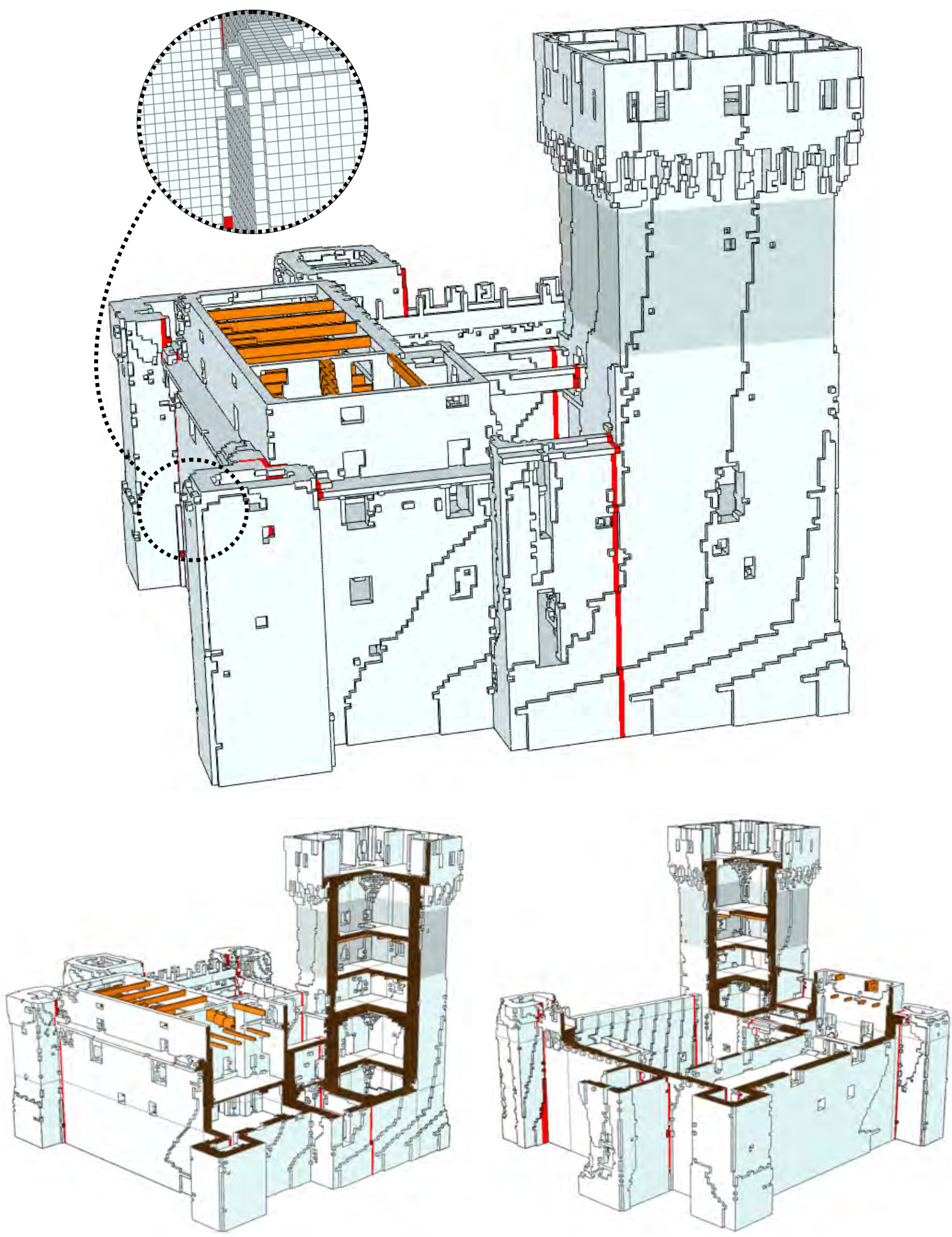

Figure 6: San Felice sul Panaro fortress FE mesh. Structural connections are highlighted in red. Note that the volume of connections is negligible in comparison to the global volume of the structure. The magnified portion shows the mesh discretization. 


\subsection{Boundary conditions and connections}

In the past, the fortress was surrounded by a moat. Therefore, the ground level is located at two different altitudes: inner ground level, located at 0.00 meters (assumed as origin of the reference system), and outer ground level, located at -3.50 meters. The boundary conditions account for this difference: all the nodes located at the moat level have clamped boundary conditions applied, whereas the elements located into the courtyard have been modeled through an elastic material to take into account the presence of the terrain (Material ID 4, [51]). For all of the following analyses, these boundary conditions have been considered. Moreover, roofing structures have been modeled as concentrated mass.

The crack pattern occurred between adjacent macro-elements (for instance the ones between towers and the curtain wall) permits us to move considerations about the structural interaction between adjacent structural elements. In particular, in Figure 7 some photos that portray different toothing levels between structural parts are reported: absence of connection between the parts, see for instance Figure 7(a) referred to N-E tower and North wall joint; low connection due to the poor masonry toothing, see for instance Figure 7(b) referred to Mastio and East wall joint; high connection due to the good texture quality of the masonry, see for instance Figure 7(c), where only the corbels exhibit a detachment from the North tower. All these aspects fit the historical evolution stages of the building $[43,44]$. The proper modeling of such features is fundamental in

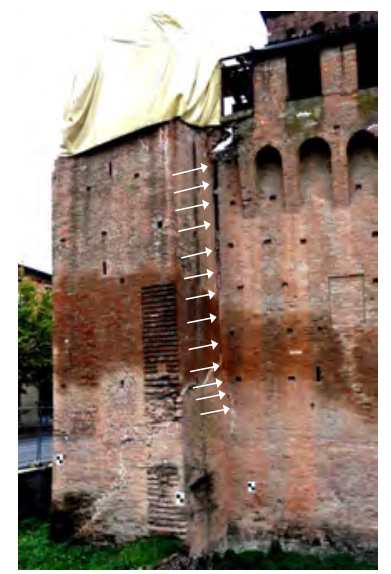

(a) N-E Tower - North wall joint: note the absence of connection between the parts

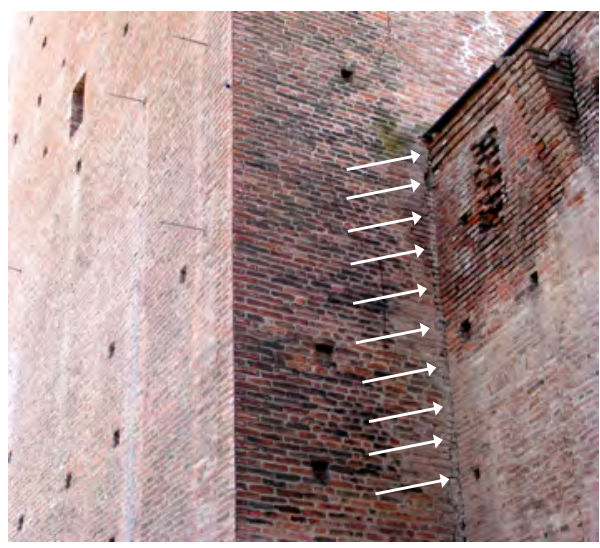

(b) Mastio - East wall joint: poor toothing quality

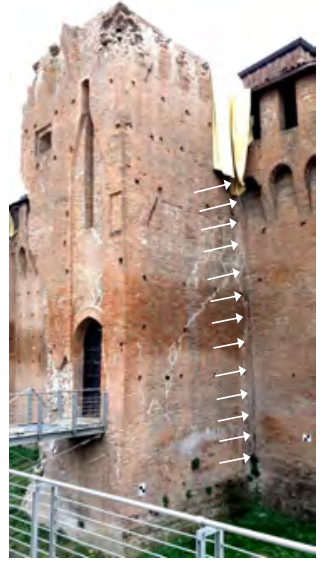

(c) North Tower - North wall joint: good quality connection

Figure 7: Connections between adjacent macro-elements of the fortress.

order to catch a plausible structural behavior of the fortress. Thereby, they need to be adequately considered in numerical models.

After an accurate analysis of the historical evolution of the fortress and a study about the adjacent macro-elements' masonry toothing (thanks to a visual aid), hypotheses about the structural connections' positions have been made. In particular, connections have been introduced in the numerical model between adjacent macro-elements built in different eras, where the poor quality of 
connections is visible and more plausible. Substantially, connections have been inserted between towers and adjacent walls. The structural connections introduced are shown in Figure 6 in red.

\subsection{Natural frequencies}

A numerical assessment of the effect of connections characterization on the dynamic behavior of the fortress has been conducted by means of natural frequencies analyses. In particular, two different connections configurations have been considered: adjacent macro-elements Fully connected and Not connected (e.g. without any toothing).

Due to its nonlinear character, the pounding between adjacent macro-elements cannot be contemplated in these linear analyses: indeed, in a Not connected configuration adjacent macroelements behave as isolated and independent structures.

The influence of connections on the dynamic behavior has been assessed by comparing results between the two connections configurations in terms of natural frequencies and modal shapes. In particular, results of the first nine natural frequencies of the fortress are reported in Table 3 for the two connections configurations. As it can be noted, the structural effect of connections on the

Table 3: Results of the first nine natural frequencies of the fortress and relative variation for the two connections configuration.

\begin{tabular}{cccc}
\hline $\begin{array}{c}\text { Mode } \\
\#\end{array}$ & $\begin{array}{c}\text { Fully con. } \\
\text { fr. }[\mathrm{Hz}]\end{array}$ & $\begin{array}{c}\text { Not con. } \\
\text { fr. }[\mathrm{Hz}]\end{array}$ & \% Var. \\
\hline \hline 1 & 2.2231 & 1.9809 & -10.895 \\
2 & 2.4278 & 2.0500 & -15.561 \\
3 & 4.0917 & 3.8555 & -5.773 \\
4 & 4.4717 & 3.8857 & -13.105 \\
5 & 4.8790 & 4.2838 & -12.199 \\
6 & 4.9832 & 4.5906 & -7.878 \\
7 & 6.8285 & 6.3173 & -7.486 \\
8 & 7.3270 & 6.9297 & -5.422 \\
9 & 8.1807 & 7.9072 & -3.343 \\
\hline
\end{tabular}

dynamic behavior of the fortress remains rather limited, with a percentage variation of the natural frequencies under the $16 \%$.

Figure 8 shows the comparison between the modal shapes of Mode \# 2 (Mastio's bending mode) for the Fully connected and Not connected configurations. As it can be observed, this modal shape does not essentially change between the two cases. On the other hand, Figure 9 shows the comparison between the modal shapes of Mode \# 3. The modal shape's change is evident: in the Not connected configuration also the Est curtain wall is activated. Similarly, in the comparison between the modal shapes of Mode \# 6 (Mastio's torsional mode), depicted in Figure 10 , it is clearly evident the modal shape's change concerning the North tower. 


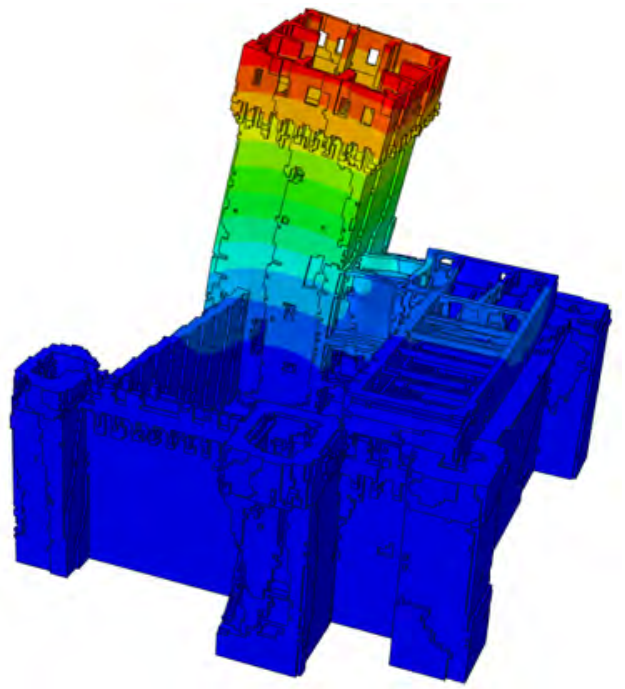

(a) Fully connected configuration. $2.4278 \mathrm{~Hz}$

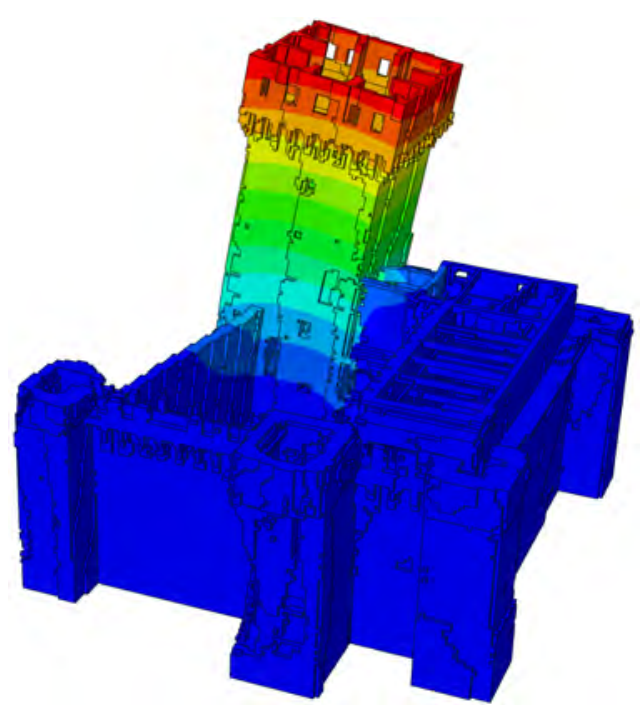

(b) Not connected configuration. $2.0500 \mathrm{~Hz}$

Figure 8: Mode \# 2.

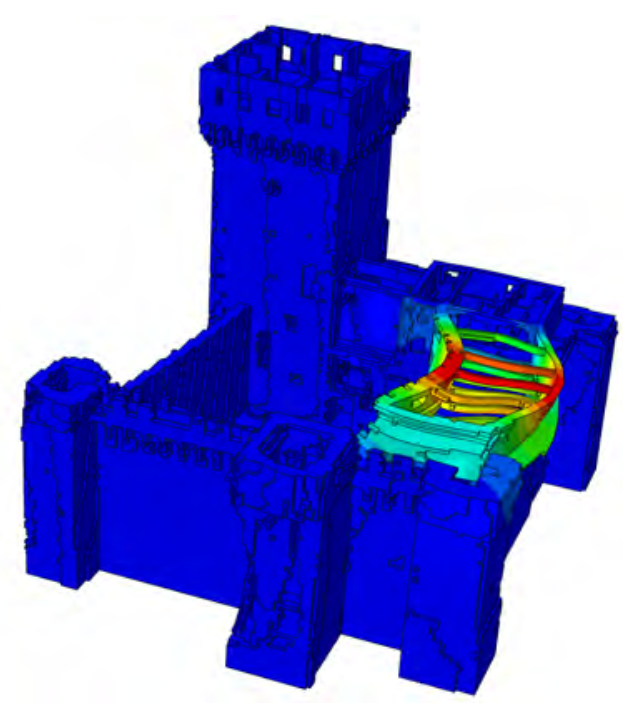

(a) Fully connected configuration. $4.0917 \mathrm{~Hz}$

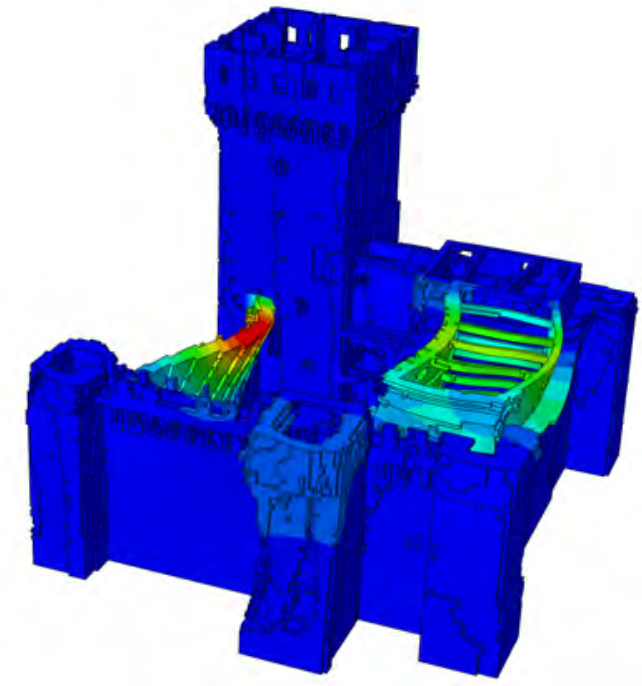

(b) Not connected configuration. $3.8555 \mathrm{~Hz}$

Figure 9: Mode \# 3. 


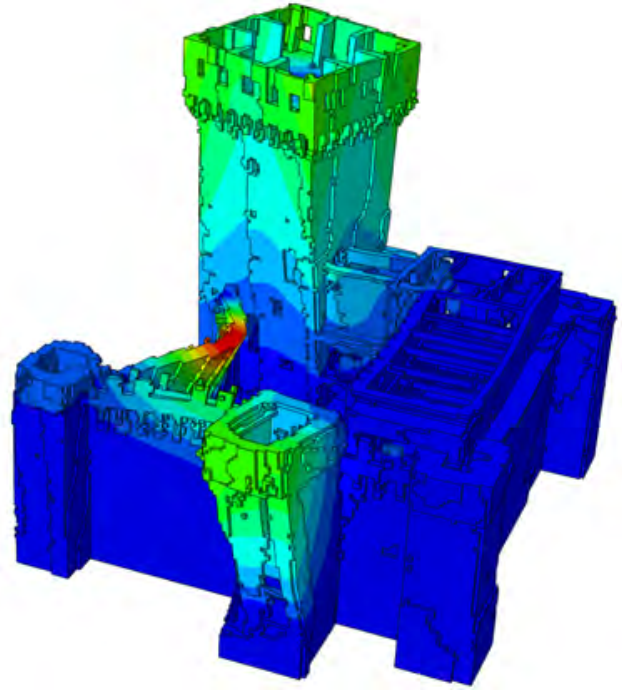

(a) Fully connected configuration. $4.9832 \mathrm{~Hz}$

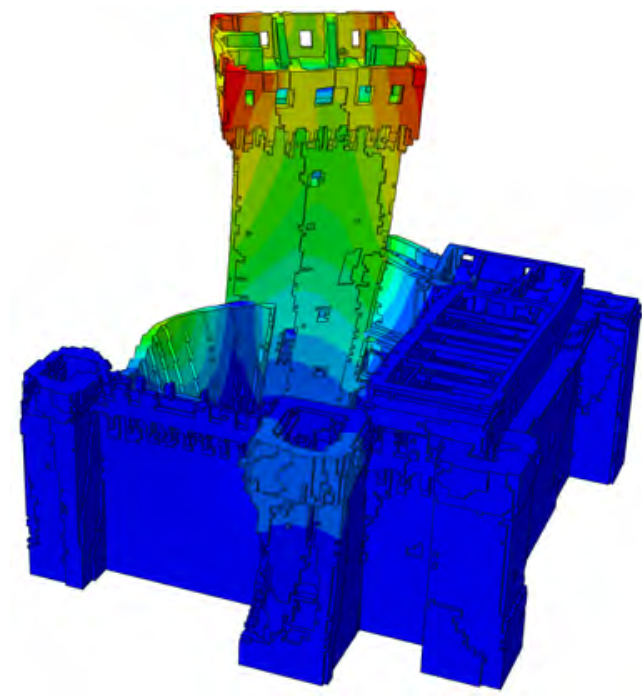

(b) Not connected configuration. $4.5906 \mathrm{~Hz}$

Figure 10: Mode \# 6. 


\subsection{Linear Static Analyses}

Although linear analyses cannot take into account the complex nonlinear mechanical behavior of masonry, they are often used in the field of numerical modeling of historical structures for the possibility of providing useful informations about the global structural behavior with a limited computational effort $[8,52,53]$.

As anticipated in the Introduction, in this study, linear static analyses have been used to conduct a numerical assessment of the structural behavior of the fortress in the spirit of $\$ 2.5$ of the Italian guidelines on cultural heritage [37]. The reliability of these analyses has been evaluated by performing a comparison between analyses results and the crack pattern suffered by the structure during the Emilia earthquake (2012). For the sake of brevity, the attention is focused on the study of the structural behavior of the fortress principal tower (Mastio) and its interaction with adjacent structural elements only. Since the Mastio showed significant damage only in the walls parallel to the E-W direction, the comparisons with the crack pattern have been performed with horizontal forces applied in the E-W direction only. For simplicity, horizontal forces proportional to the Mastio's first bending modal shape in E-W direction (Mode \#2, Figure 8), with a maximum horizontal acceleration equal to $0.3 \mathrm{~g}$, have been applied together with vertical dead loads.

Analyzing the masonry toothing between Mastio and its adjacent macro-elements, considering also the fortress historical evolution, three different connections levels have been assumed along the connection zones between Mastio and its adjacent macro-elements, as reported in Figure 11. With reference to Figure 11, the portion A has been supposed as Partially connected with reduction

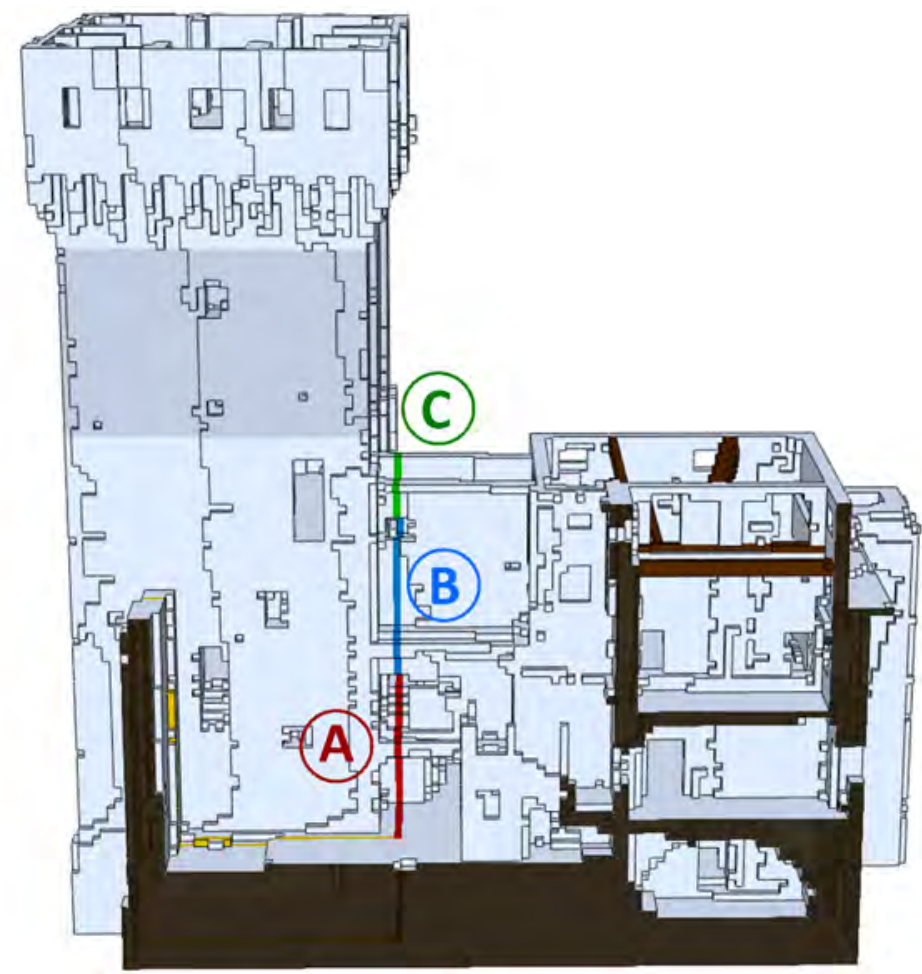

Figure 11: San Felice sul Panaro Fortress FE mesh. Detail of Mastio’s connections. 
factors (see Table 1) $\gamma_{E t}=\gamma_{G t}=1.6$ due to its quite good masonry toothing, the portion B as Partially connected characterized by a poor toothing quality with $\gamma_{E t}=\gamma_{G t}=10$, and the portion C Not connected since the absence of toothing between the parts is clear. Finally, for simplicity, it has been assumed $\gamma_{G c}=1$ for all the portions.

The results of linear static analysis for a West directed force are depicted in Figure 12 for the South front and in Figure 13 for the North front. As it can be easily realized, in this case the connections tend to be in compression and, hence, these results refer to the condition of connections closing. In particular, concerning the South front, the stress states in terms of normal vertical stress component and in-plane tangential stress component are depicted in Figures 12(a) and 12(b), respectively. As it can be noticed, the recovered stress fields are well represented over the structural domain and are not influenced by the jagged representation of the geometry. However, if needed, further enhancements of the recovered fields can be achieved by means of stress recovery procedures, see for instance $[54,55]$.

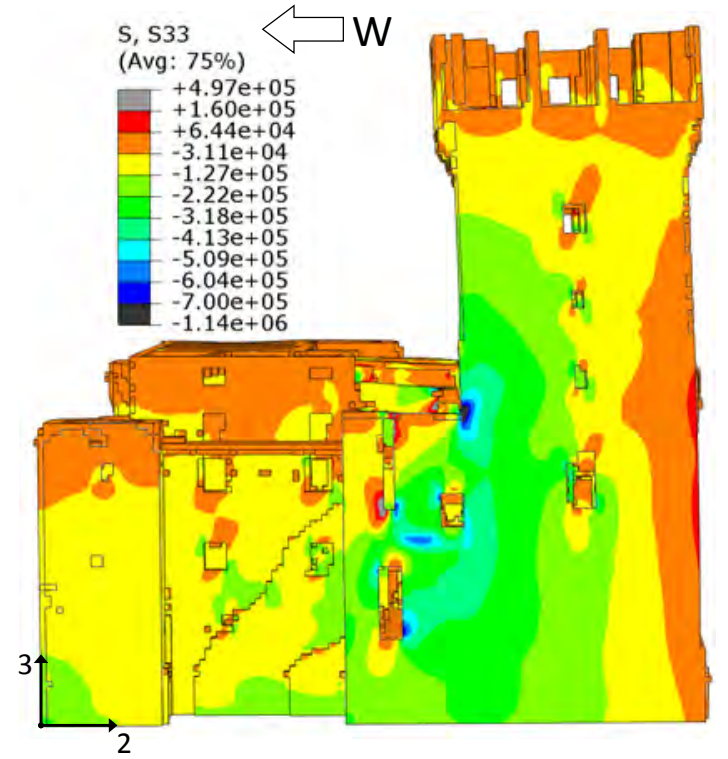

(a) Vertical Stress $(\mathrm{Pa})$

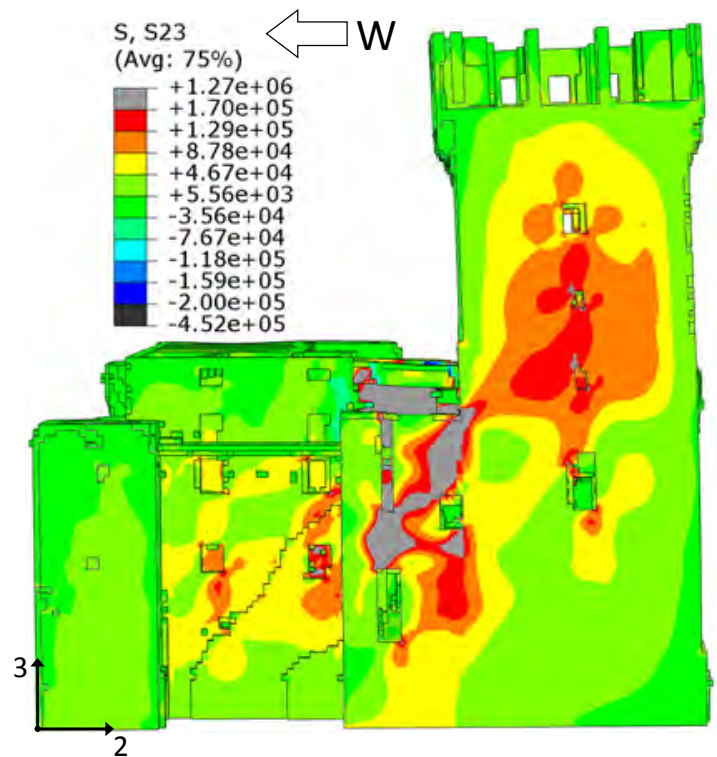

(b) Tangential Stress $(\mathrm{Pa})$

Figure 12: Linear static analysis results relative to a West directed force, South front.

Moving to the Mastio's North front, Figure 13 shows the comparison between the stress state (reported in Figure 13(a) in terms of maximum principal stress) and the crack pattern which is characterized by a curved crack, highlighted by a dotted line in Figure 13(a) and by arrows in Figure 13(b). As it can be noted, they are in good agreement: the emphasized crack is almost perpendicular to the grater maximum principal stress' spatial vectors. 


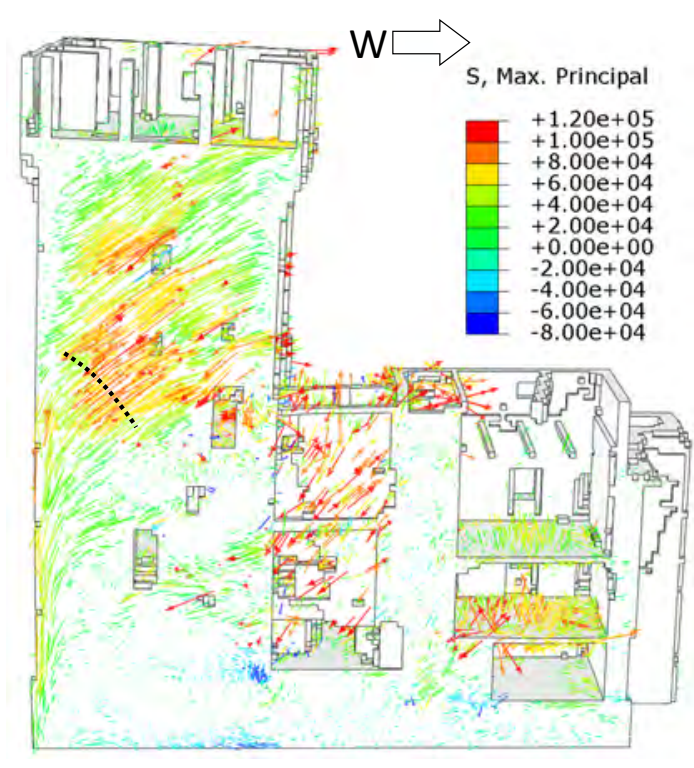

(a) Maximum Principal Stress (Pa)

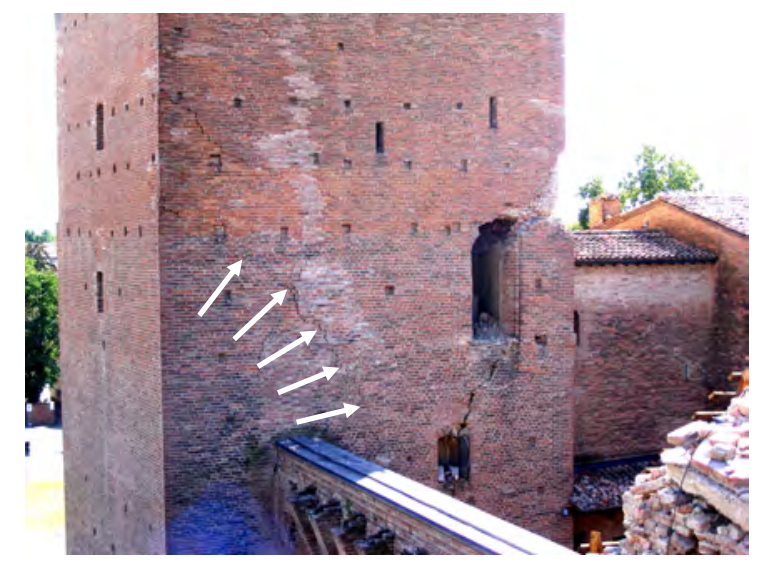

(b) Crack pattern

Figure 13: Comparison between linear static analysis results relative to a West directed force and the crack pattern suffered by the structure during the Emilia earthquake, North front. 
The results of the linear static analysis for an East directed force are shown in Figure 14 for the South front and in Figure 15 for the North front. As it can be easily argued, in this case there is an opening of connections since the joint between the Mastio and its adjacent macro-element is in a tensile stress state. Similarly to the previous case, we propose a comparison between linear static analysis results in terms of maximum principal stress and the crack pattern suffered by the structure. Regarding the South front, the stress state is shown in Figure 14(a) and the crack pattern in Figure 14(b). Segments $\overline{A B}, \overline{C D}, \overline{E F}$ and $\overline{G H}$ shown in Figure 14(a) correspond to the major

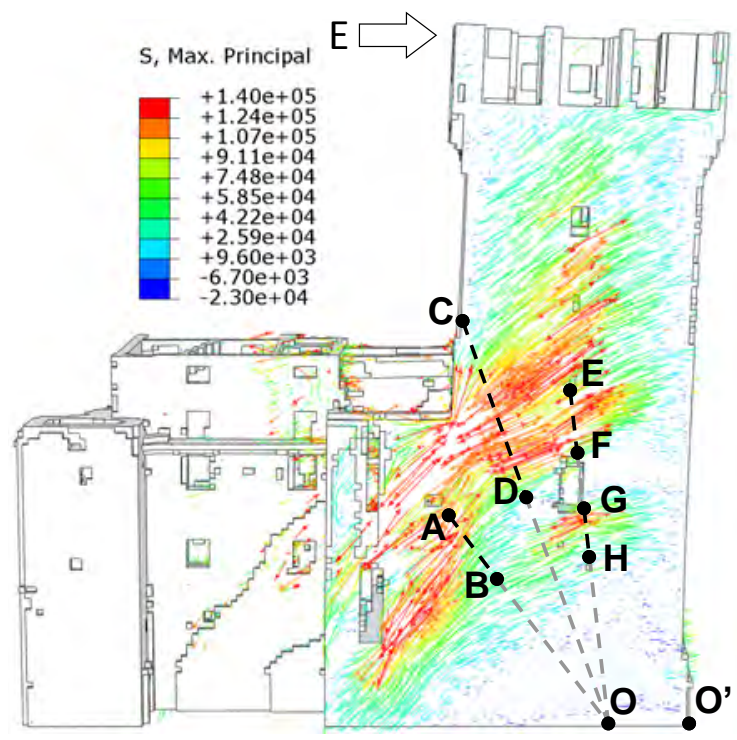

(a) Maximum Principal Stress (Pa)

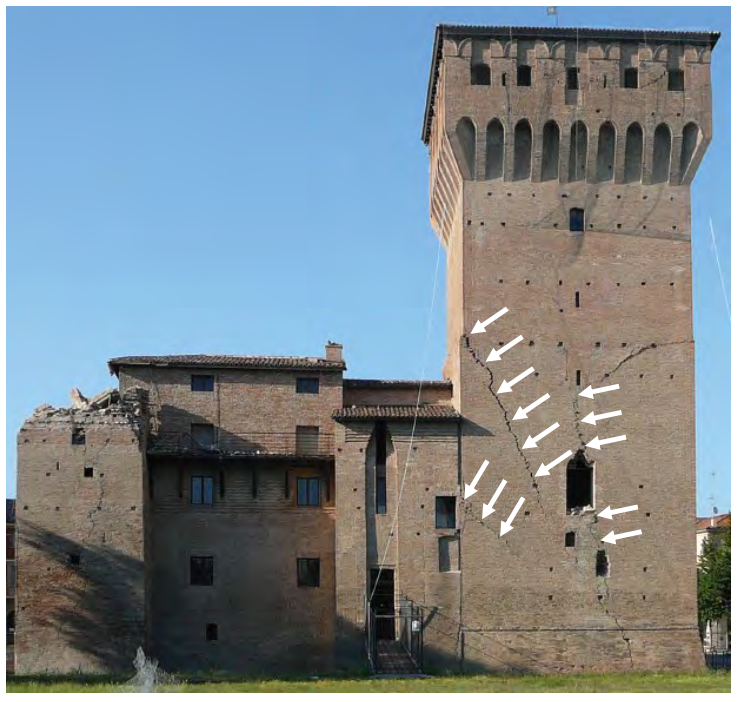

(b) Crack pattern

Figure 14: Comparison between linear static analysis results relative to a East directed force and the crack pattern suffered by the structure during the Emilia earthquake, South front. Segments $\overline{A B}, \overline{C D}, \overline{E F}$ and $\overline{G H}$ correspond to the major cracks.

cracks of the Mastio's South front indicated by arrows in Figure 14(b). As it can be noted, the maximum principal stresses are almost perpendicular to the highlighted segments (Figure 14(a)). In this sense, it can be stated that the stress state and the crack pattern shown in Figure14 are in good agreement. Moreover, it can be noticed that prolonging these segments they all run into point $O$. Thereby, an hypothetic point between $O$ and $O^{\prime}$ can be considered as the center of rotation for a plausible overturning mechanism.

Concerning the Mastio's North front, the linear static analysis results relative to a East directed force are shown in Figure 15. In particular, the distribution of the maximum principal stresses is shown in Figure 15(a) and the crack pattern in Figure 15(b). Also in this case there is a good agreement between the maximum principal stresses distribution and the cracks suffered by the Mastio's trunk.

As already mentioned, one of the features of the proposed modeling strategy is its ability to give a fine geometrical representation of the whole building, including the secondary structural elements. Among these, Figure 16 focuses the attention on the stiffening walls located in the Mastio's top. In particular, Figures 16(a) and 16(b) show the maps of the vertical stress component 


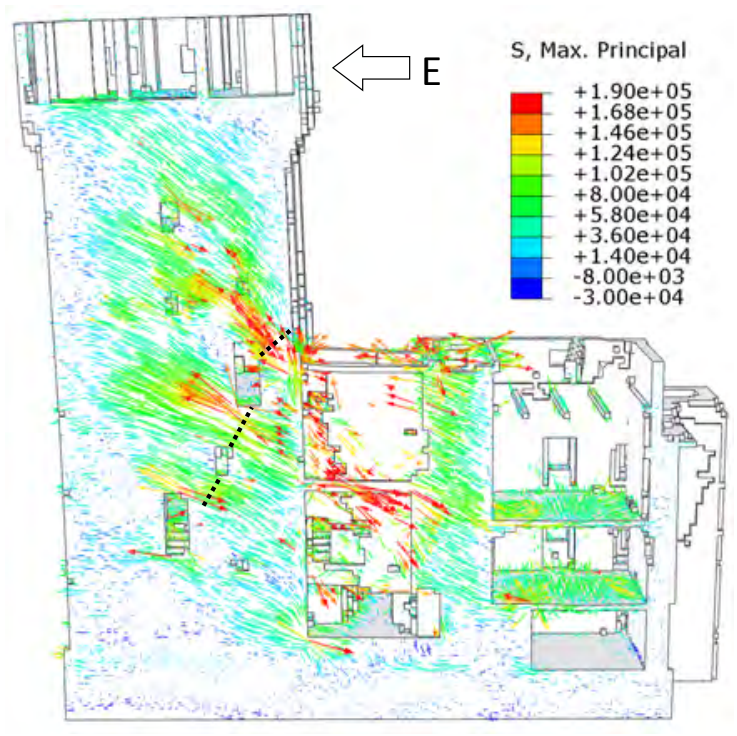

(a) Maximum Principal Stress (Pa)

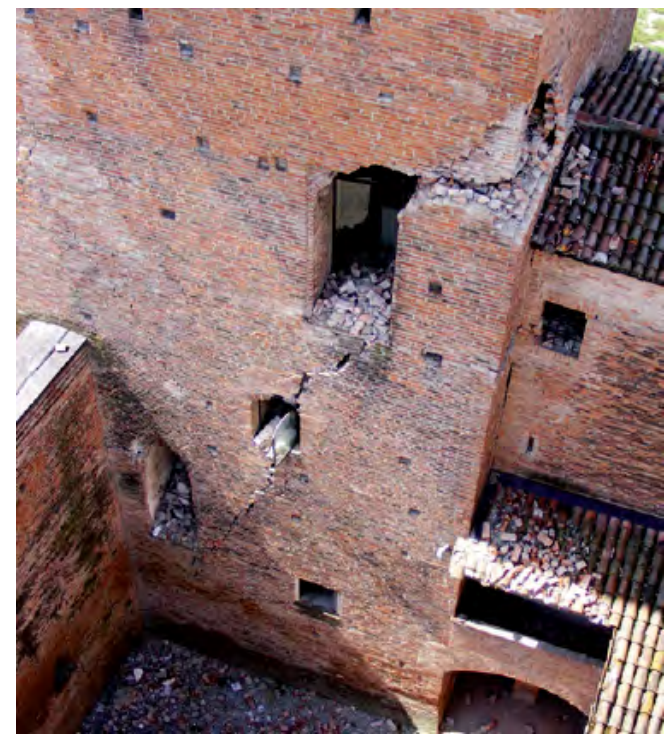

(b) Crack pattern

Figure 15: Comparison between linear static analysis results relative to a East directed force and the crack pattern suffered by the structure during the Emilia earthquake, North front.

due to a horizontal East directed and West directed force, respectively, and Figures 16(c) and 16(d) show the crack pattern. Inspecting Figures 16(a) and 16(b) reveals the presence of compression and tensile stress peaks at the base of the E-W directed stiffening walls. This is in very good agreement with the crack pattern suffered by these stiffening walls (Figure 16(c)), where a subhorizontal crack is clearly evident (Figure 16(d)).

\subsection{Nonlinear Analyses}

In order to assess the seismic vulnerability of the main tower of the San Felice sul Panaro fortress and the reliability of the semi-automatically generated mesh, several nonlinear static pushover analyses have been carried out.

\subsubsection{Constitutive model}

The nonlinear mechanical behavior of masonry has been modeled by means of the Concrete Damage Plasticity (CDP) material model, which is available within the Abaqus software. Even though the CDP was conceived for isotropic brittle materials like concrete, it has been extensively used also for quite anisotropic materials such as masonry through a parameters' adaptation [56, 57, $58,59,60]$. The CDP model allows the analysis of materials with different strength in tension and in compression, assuming different damage parameters, see Figure 18. The behavior in tension is linear elastic till the stress peak $\sigma_{t 0}$ is reached. Afterwards, micro-cracks starts to propagate in the material and the stress-strain curve drops down following a softening branch. The decay-rate at which the curve decreases is defined by the factor $d_{t}$ (Figure 17(a)). Under axial compression the response is linear up to the yield stress $\sigma_{c 0}$, then hardening usually occurs before compression crushing initiates, which is represented by a softening branch beyond the peak stress $\sigma_{c u}$ (Figure 


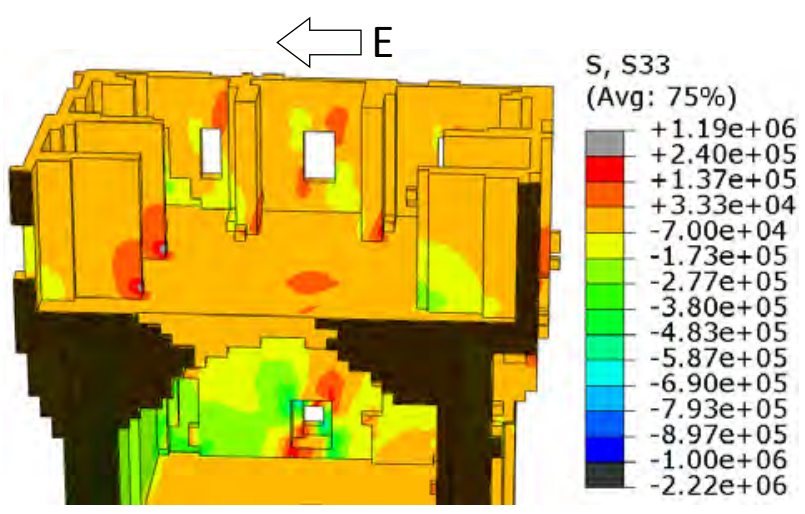

(a) East horizontal force: vertical stress $(\mathrm{Pa})$

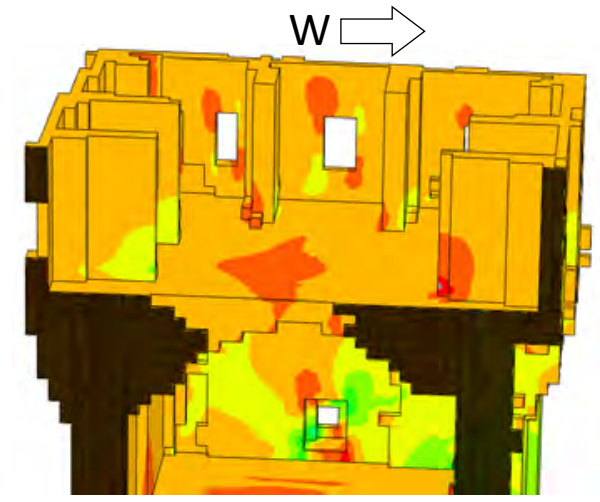

(b) West horizontal force: vertical stress $(\mathrm{Pa})$

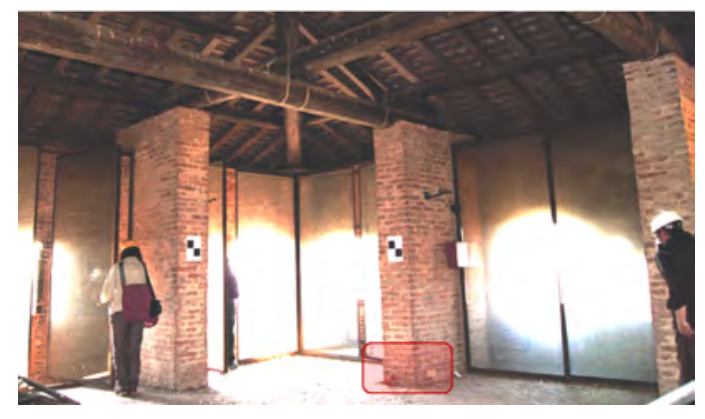

(c) Mastio's top

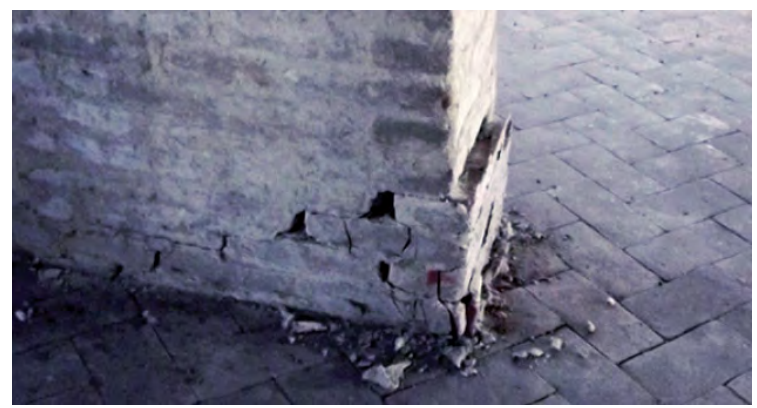

(d) Particular of the crack pattern related to the red highlighted square in Figure 16(c)

Figure 16: Comparison between numerical results and the crack pattern on Mastio's top stiffening walls.

17(b)). The damage variable in tension $d_{t}$ and in compression $d_{c}$ are defined by the following standard relationships:

$$
\begin{aligned}
& \sigma_{t}=\left(1-d_{t}\right) E_{0}\left(\varepsilon_{t}-\varepsilon_{t}^{p l}\right) \\
& \sigma_{c}=\left(1-d_{c}\right) E_{0}\left(\varepsilon_{c}-\varepsilon_{c}^{p l}\right)
\end{aligned}
$$

where $\sigma_{t}$ and $\sigma_{c}$ are the mono-axial tensile and compressive stress, $E_{0}$ is the initial elastic modulus, $\varepsilon_{t}$ and $\varepsilon_{c}$ are the total strain in tension and in compression, $\varepsilon_{t}^{p l}$ and $\varepsilon_{c}^{p l}$ are the equivalent plastic strain in tension and in compression. Since the compression stresses are always far from the yield stress (as experienced in linear analyses), the damage is assumed to be active only in tension, thus the reduction of the material strength and stiffness has been applied only in the case of principal stress exceeding the maximum admissible tensile strength. The material elastic modulus has been gradually reduced every time the strain reached a critical value in tension.

The implemented strength domain is a standard Drucker-Prager surface modified with a $K_{c}$ parameter, see Figure 18, representing the ratio between the distance from the hydrostatic axis of the maximum compression and tension respectively. The value of $K_{c}$ has been kept equals to $2 / 3$ as suggested by the users guide [47]. Furthermore, a regularization of the tensile corner has been assumed in the constitutive law. This regularization is obtained with a further correction parameter, called eccentricity. Such a parameter indicates the rate at which the plastic flow potential approaches the asymptote, i.e. the flow potential tends to a straight line as the eccentricity 


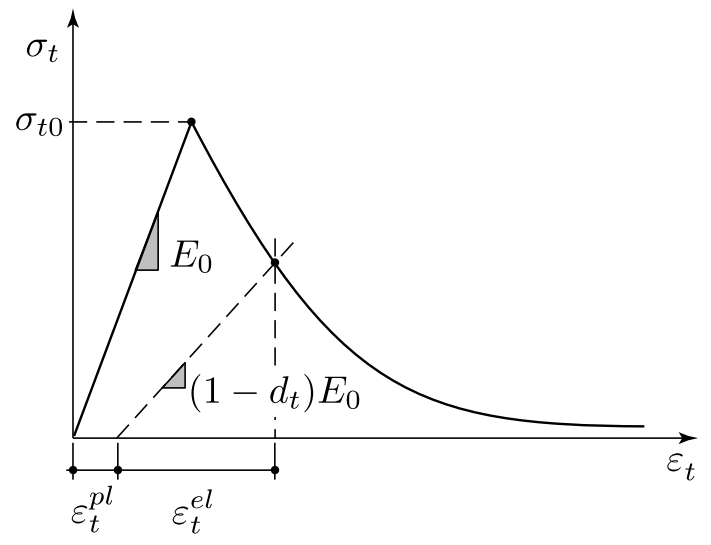

(a) Tensile behavior

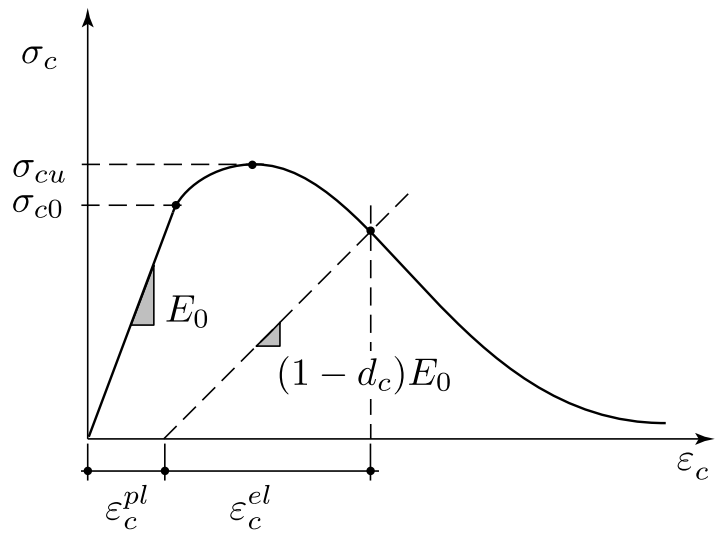

(b) Compression behavior

Figure 17: Compression and tensile mono-axial inelastic curves [47].

tends to zero. The default value equal to 0.1 has been adopted. Smaller values may cause convergence problems when the material is subjected to low confining pressures because of the very tight curvature [47].

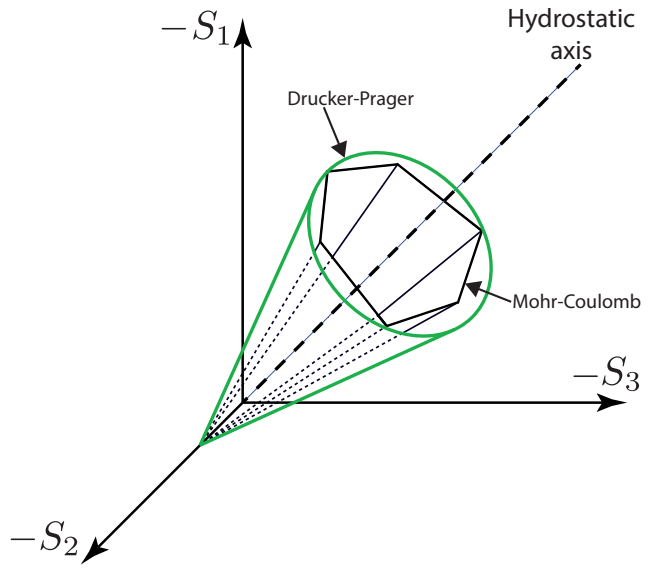

(a) Yield surfaces in the Westergaard space

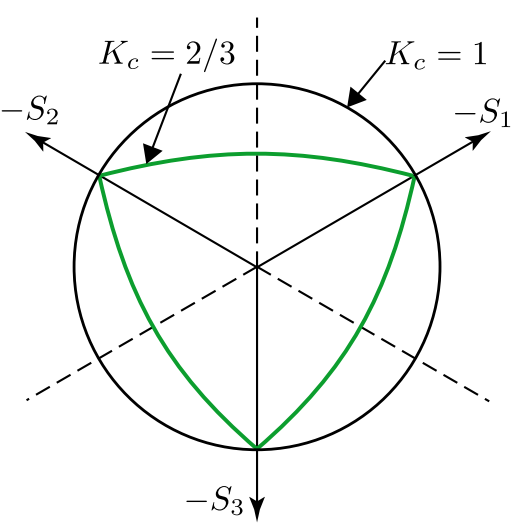

(b) Yield surfaces in the deviatoric plane and meaning of the $K_{c}$ parameter

Figure 18: Modified Druker-Prager strength domain [47].

For what concerns the dilatation angle, a value of $10^{\circ}$ is adopted for the inelastic deformation in the nonlinear range, in agreement with experimental evidences available in the literature. The ratio between the bi-axial, $f_{b 0}$, and mono-axial, $f_{c 0}$, compression strength has been kept equal to 1.16 as suggested in [61].

Material models exhibiting softening behavior and stiffness degradation often lead to severe convergence difficulties in numerical analyses. Some of these convergence difficulties can be overcome by using a viscoplastic regularization of the constitutive equations. The CDP model can be regularized using viscoplasticity, i.e. permitting stresses to be outside of the yield surface, 
through the viscosity parameter. Using the viscoplastic regularization with a small value for the viscosity parameter (small compared to the characteristic time increment) usually helps to improve the rate of convergence of the model in the softening regime, without compromising results. On the other hand, high values of such a parameter can lead to an overestimation of the peak base shear. A sensitivity analysis of the viscosity parameter influence on the case study is reported in Section 4.5.3. Consequently, a value of the viscosity parameter equal to 0.002 has been assumed, also in agreement with [59] for a very similar historical structure. A summary of the parameters adopted in the nonlinear analyses is reported in Table 4.

Table 4: Concrete Damage Plasticity parameters for masonry according to [56, 57, 59].

\begin{tabular}{ll}
\hline Parameter & Value \\
\hline \hline Dilatation angle & $10^{\circ}$ \\
Eccentricity & 0.1 \\
$f_{b 0} / f_{c 0}$ & 1.16 \\
$K_{c}$ & $2 / 3$ \\
Viscosity Parameter & 0.002 \\
\hline
\end{tabular}

In the absence of availability of in situ test results for the fortress, it is necessary to refer to what is stated by Italian Code for existing masonry buildings. According to the Italian Code NTC 2008 [49] and subsequent Explicative Notes [50], the mechanical properties assumed for masonry material depend on the so-called knowledge level LC. For the cases at hand, a LC1 level (the lowest) is assumed in the absence of specific in situ test results. As a consequence, the values adopted for cohesion and masonry elastic modulus are taken in agreement with Explicative Notes [50] of the Italian code NTC 2008 [49], assuming a masonry typology constituted by clay bricks with very poor mechanical properties of the joint and quite regular courses. The inelastic stressstrain relationships adopted in the constitutive model of masonry are those reported in Figure 19 for the compression and tensile mono-axial curves. Furthermore, a linear reduction until the $90 \%$ of the Young's modulus with respect to $E_{0}$ for a deformation which corresponds to the lowest extremity of the softening branch of the tensile law (Figure 19) has been assumed.
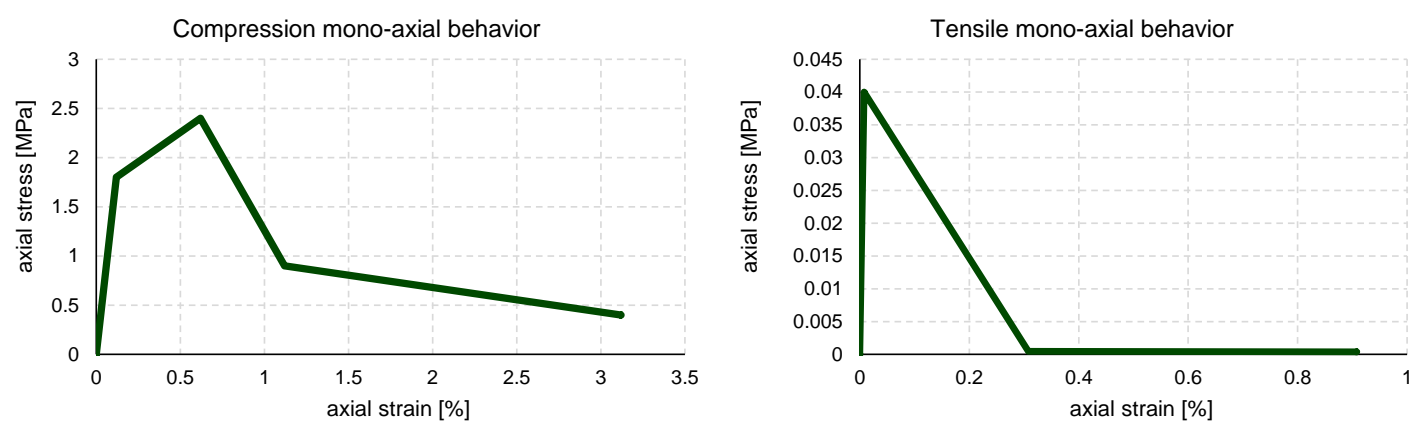

Figure 19: Compression and tensile mono-axial inelastic curves for masonry according to [49, 50].

Mechanical properties adopted for masonry are also compatible with the works presented in $[18,59,62]$ where the numerical analyses of three case studies of coeval and very similar masonry 
towers, which are located in Finale Emilia at approximately $10 \mathrm{~km}$ far from San Felice sul Panaro, have been presented. Indeed, it is worth-noting that middle-age masonries in the area hit by the 2012 seismic events seem to exhibit a quite similar and low strength [63].

Since the findings of experimental campaigns are not available and it is still unknown how the tie-rods are linked to masonry, for the sake of safety we assumed the same inelastic parameters for the masonry of the Mastio's trunk top part (dark gray in Figure 6).

In traditional numerical modeling operations, masonry vaults and timber floors are commonly modeled through equivalent linear elastic plates (i.e. with the same in-plane stiffness). Such a simplification is commonly accepted in literature $[64,65]$ for the assessment of the global structural behavior of buildings. Here, the jagged representation of vaults is automatically meshed but, since we aim at assessing the global seismic behavior of the tower, their mechanical properties are kept linear also in nonlinear pushover analyses.

\subsubsection{Simplified pushover method}

A simplified displacement-based procedure using nonlinear static pushover analyses (called N2 method [66]) is adopted for the seismic verification of the global performance of the main tower of the fortress of San Felice sul Panaro. The elastic spectrum used for the N2 safety assessment method is the one provided by the Italian standard [49] for the site of San Felice sul Panaro with a return period equal to 975 years. This code spectrum is essentially compatible with the real spectra of the actual earthquake recorded on May 29th 2012 at the SANO station located at approximately 150 meters from the fortress [67], see Figure 20.

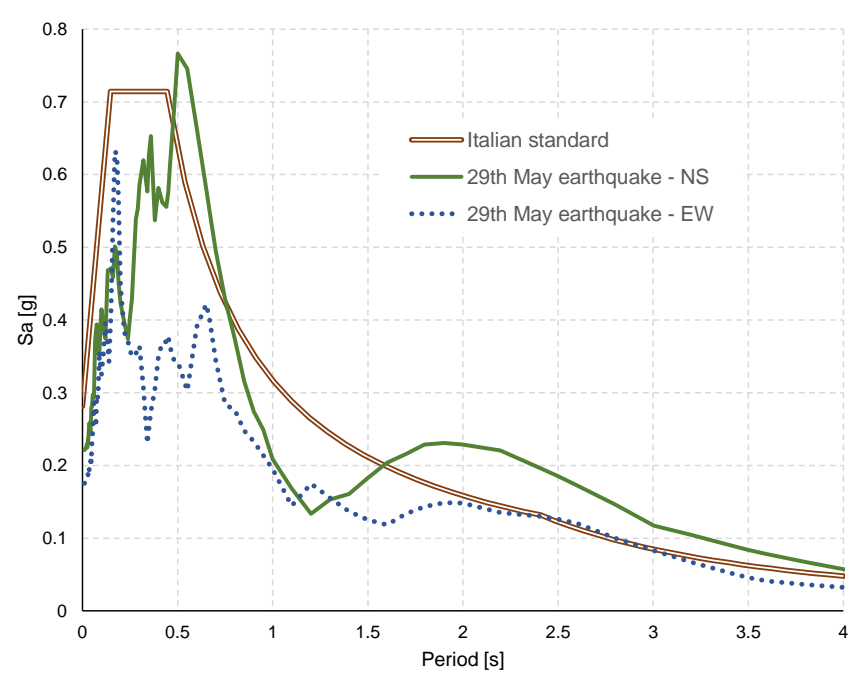

Figure 20: Comparison between the code spectrum and the spectra obtained from the actual earthquake recorded on May 29th 2012 [49, 67].

According to the Italian Code $[49,50]$, when dealing with pushover analyses, the response of the structure should be investigated along the geometrical orthogonal axes $\mathrm{X}$ and $\mathrm{Y}$ (in this case N-S and E-W directions, respectively), in both the positive and negative directions. Italian Code also prescribes the evaluation of the load carrying capacity by means of two configurations 
of lateral forces: a first distribution of forces derived by the assumption of a linear variation of acceleration along the height (G1) and a second distribution with uniform acceleration (G2). For the tower under consideration, distribution G1 always provides collapse accelerations lower than those provided by distribution $\mathrm{G} 2$, therefore the reduction of the structure to a SDOF (single degree of freedom) system is done with reference to distribution G1.

The numerical analyses are conducted using an arc length procedure to deal with possible softening in the global pushover curve, up to a reasonably large displacement of a control point placed at the top of the tower.

The choice of the control point for pushover analyses of historical monumental buildings is rather critical since their behavior is rarely global. Therefore, as stated in [68], instead of the displacement of a single control node it is preferable to use the average displacement of several nodes at the same level. According to this, the average displacement of the twelve nodes evenly spaced at the top floor of the tower shown in Figure 21 has been computed for each step and considered in the pushover curves.

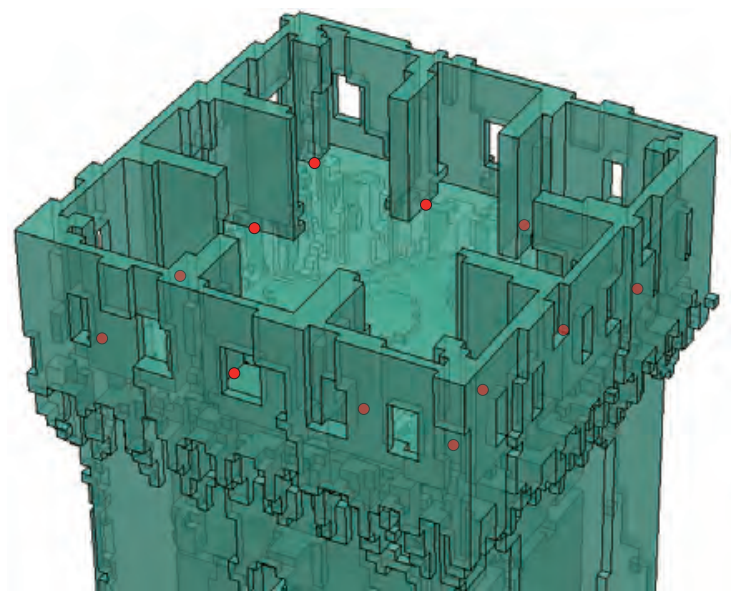

Figure 21: Nodes considered for the computation of the top displacement.

It should be pointed out that, even in the presence of softening in the constitutive model as in the present damage-plasticity one, this is hardly visible in the global pushover curves, as already experienced in [56, 59, 62]. Nevertheless, the Italian guidelines on cultural heritage [37] allows the reduction to a SDOF system even without any visible softening of global pushover curve. Indeed, in [37] considering the difficulties in the definition of the displacement at the ultimate limit state, it is recommended to evaluate the ratio between the elastic limit base shear and the ultimate shear of the bi-linear system (imposing an energy balance). Such a ratio cannot exceed a maximum admissible value, defined on the basis of the ductility and dynamic features of each construction typology, and in any case ranging between 3 and 6. As observed in [62], in case of masonry towers, which may be roughly idealized as cantilever beams, the ratio between ultimate and elastic limit load could be further reduced. In particular, for masonry towers very similar to the presented one, in [62] the value of 1.8 has been suggested. This value is assumed also in the present paper.

\subsubsection{Numerical results}


As already mentioned in Section 4.5.1, the choice of the viscosity parameter could lead to an overestimation of the peak base shear in pushover analyses. In order to have a quantitative evaluation of its influence on the case study under consideration, a sensitivity analysis has been performed by changing its value from 0 to 0.002 for a chosen load case (G1 distribution, East directed force). Figure 22 illustrates the pushover curves of the chosen load case obtained by adopting a viscosity parameter equal to $0.0001,0.0004$ and 0.002 , respectively (for values lower than 0.0001 the analyses were prematurely aborted). As a result, a slight overestimation of the peak base shear and a substantial saving of the computational time have been obtained using the value equal to 0.002 with respect to 0.0001 . Such an over-prediction seems to be included within the engineering practice acceptability and, therefore, the authors adopted the value 0.002 for the other load cases.

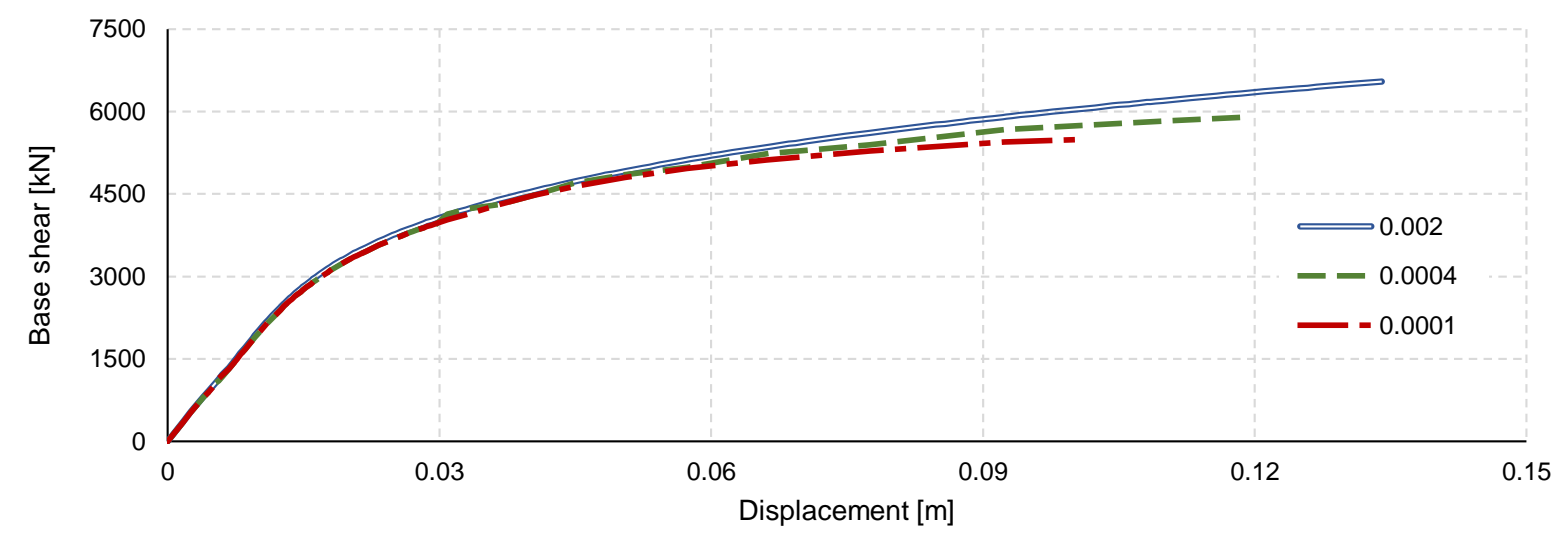

Figure 22: Influence of the viscosity parameter on a pushover curve.

The obtained pushover curves are collected in Figure 23 for each direction of the horizontal forces, while the relative bi-linear capacity curves of the equivalent SDOF systems and the results of the N2 safety assessment are reported in Figure 24. The comparison between damage contour plots of the pushover analyses and the actual crack pattern of the tower is shown in Figures 25, 26, 27, 28 for East, West, South and North directed forces, respectively. Only the sides parallel to the direction of the horizontal force are reported in such figures since the other sides do not show significant damage. The damage contour plots are referred to the seismic demand condition.

As pointed out in Figure 24, the check done by means of the N2 safety assessment method is positive for each direction of the horizontal forces even if the East directed force case, which presents the lowest safety index, is very close to one. This finding could suggest that for the considered seismic action (compatible with the occurred earthquake) the tower is prone to collapse, and by inspecting the actual damage pattern it appears reasonable. Moreover, form the East directed force results it emerges a clearly minor capacity curve and a more widespread damage distribution with respect to the other analyses results. This is in very good agreement with the damage experienced by the Mastio during the Emilia earthquake. Indeed, the sides of the tower parallel to the E-W direction, in particular toward East (see Figure 25), much suffered the occurred earthquake plausibly due to the presence of several almost-aligned openings (particularly in the North front, see Figure 25(b)). 


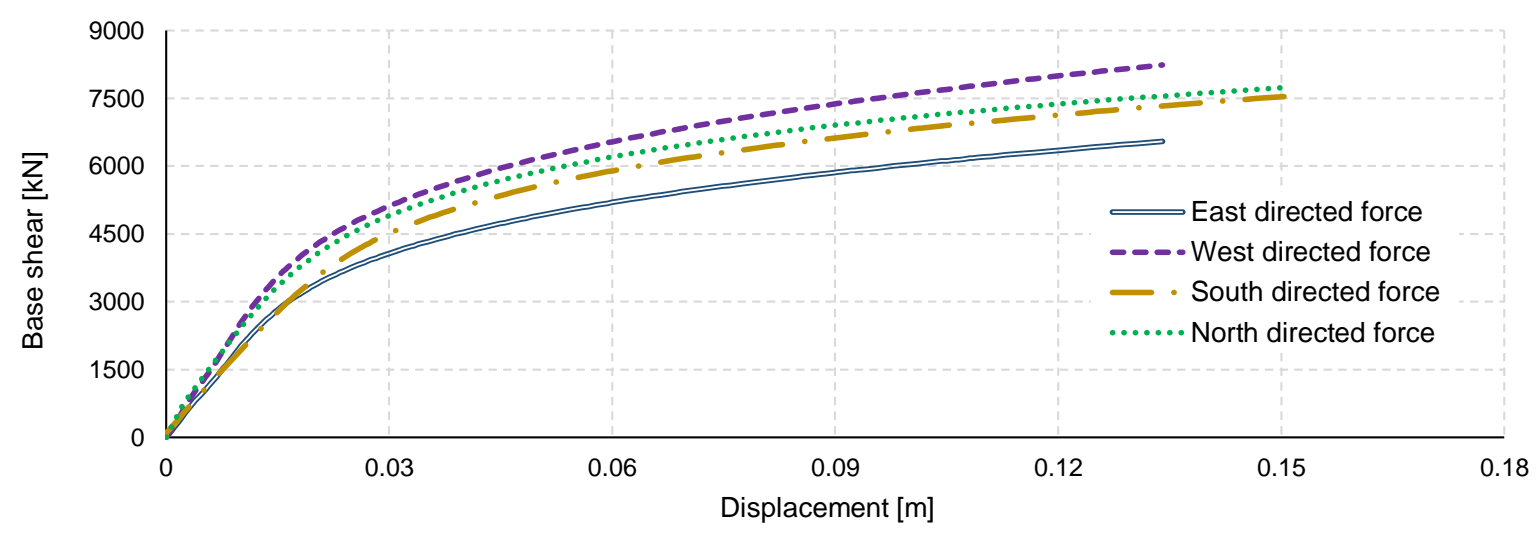

Figure 23: Pushover curves.

In general, a good agreement between the damage contour plots and the crack pattern of the tower has been achieved either for main cracks (Figures 25(a), 25(b), 27(b)) or for minor cracks (Figures 26(a), 26(a), 28(a)) and local failures (Figures 27(a), 28(b)). In particular, main cracks are predicted quite accurately in terms of both position and direction, whereas minor cracks are reproduced more coarsely. This could be addressed to the fact that minor cracks are more influenced by the peculiar masonry texture than main and large cracks, and the actual masonry texture is not contemplated in the adopted continuum model. In addition, several minor cracks appeared in the tower but they are rather narrow and could be almost imperceptible to the naked eye (e.g. Figure 28(a)). This is probably due to the presence of steel tie-rods in the Mastio's trunk top part, added in the 90s, which may have limited the cracks opening. In order to detect the presence of minor cracks, the thermographic imaging support could reveal useful. Accordingly, in Figures 25(a) and 26(a) thermal images have been superimposed on traditional photos. In all, such results further consolidate the validation of the semi-automatically generated FE model, presented in Section 4.4.

Finally, it is worth noting that the generated model benefits from the regularity of the hexahedral mesh which certainly improves the convergence of advanced numerical analyses such as nonlinear analyses with complex damage-plasticity constitutive laws. 


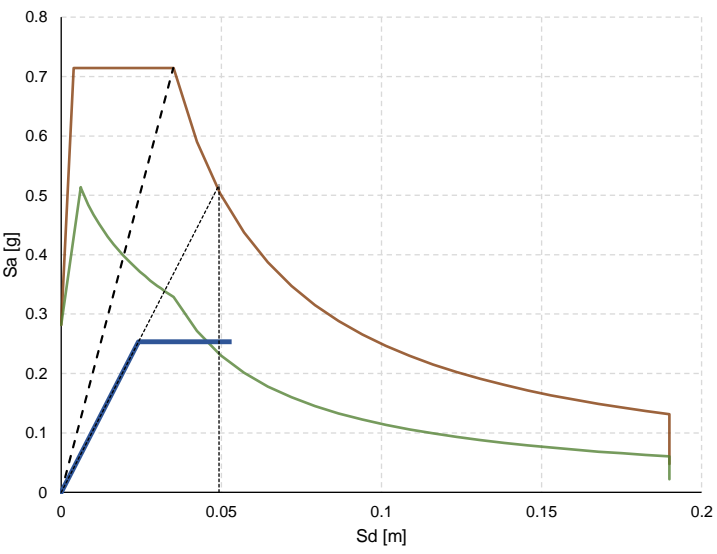

East directed force. Safety index equal to 1.065

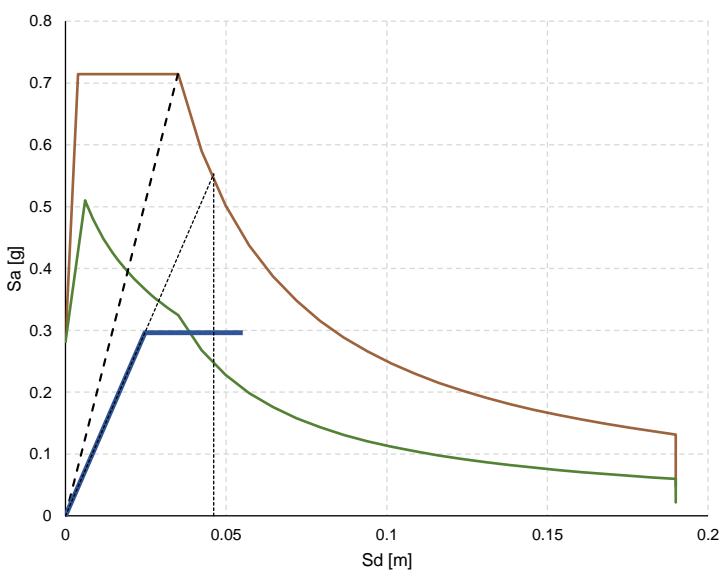

South directed force. Safety index equal to 1.180

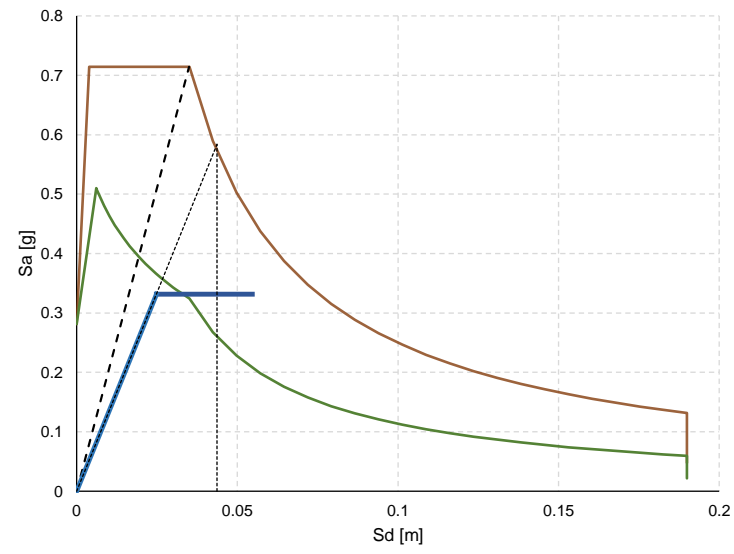

West directed force. Safety index equal to 1.251

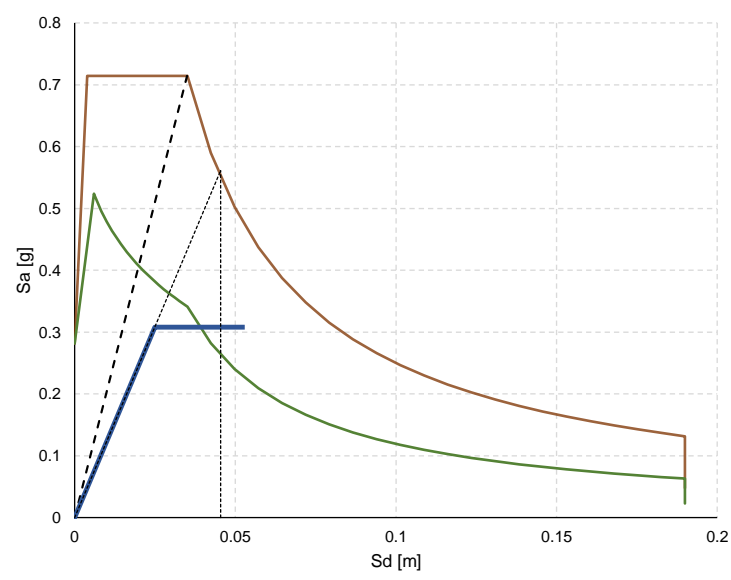

North directed force. Safety index equal to 1.148

Figure 24: Results of N2 safety assessment. Safety indexes are computed according to [37, 49, 50], i.e. through the ratio between the displacement capacity and the displacement demand. 

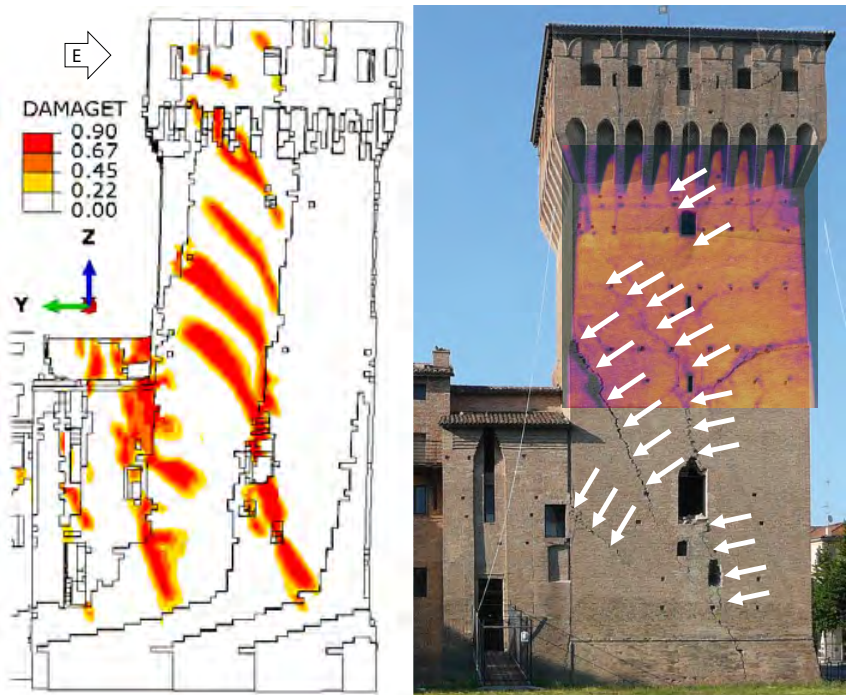

(a) South front. Superposition of a thermal image on a traditional photo

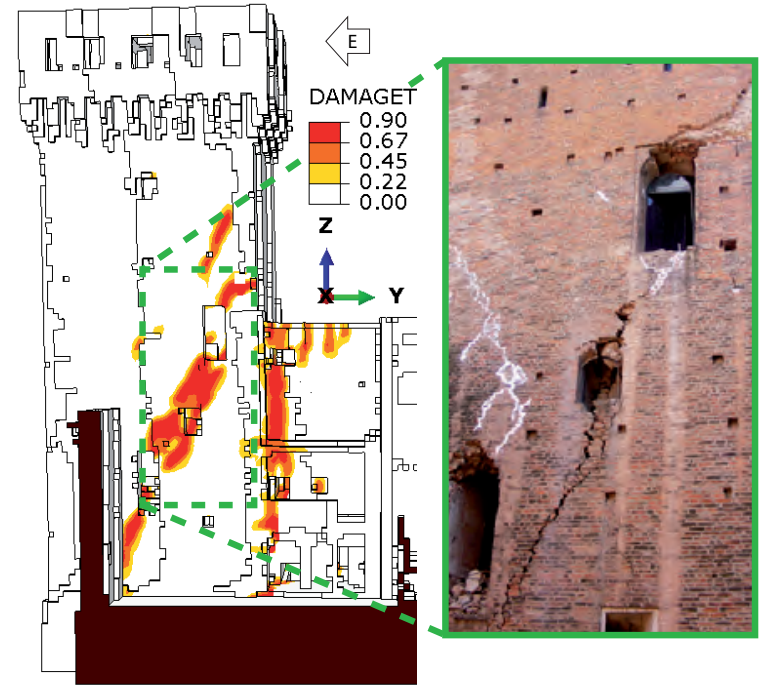

(b) North front

Figure 25: Pushover analyses with horizontal East directed force. Comparison between damage contour plots and the crack pattern. 


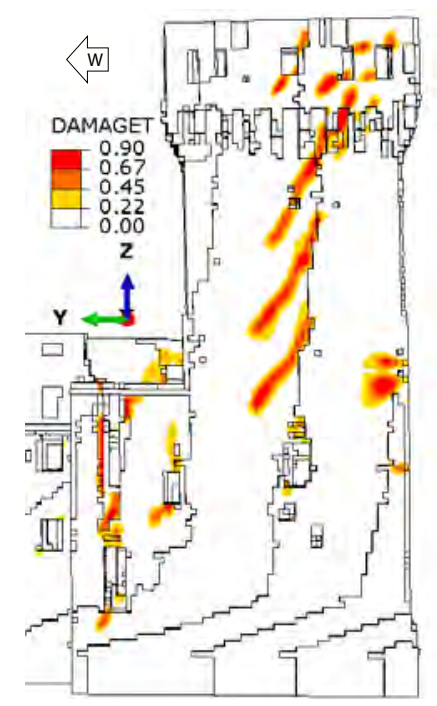

(a) South front. Superposition of a thermal image on a traditional photo
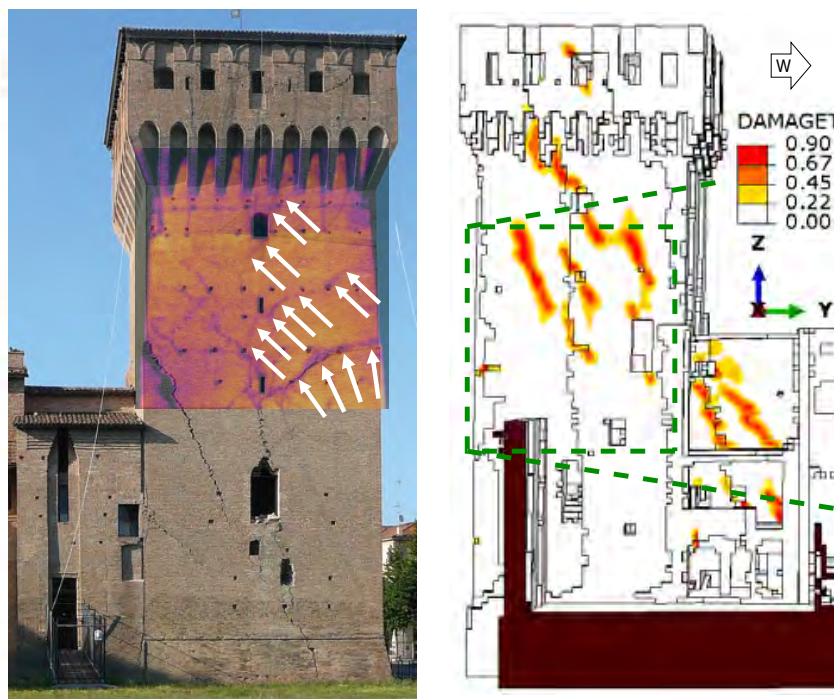

(b) North front

Figure 26: Pushover analyses with horizontal West directed force. Comparison between damage contour plots and the crack pattern.

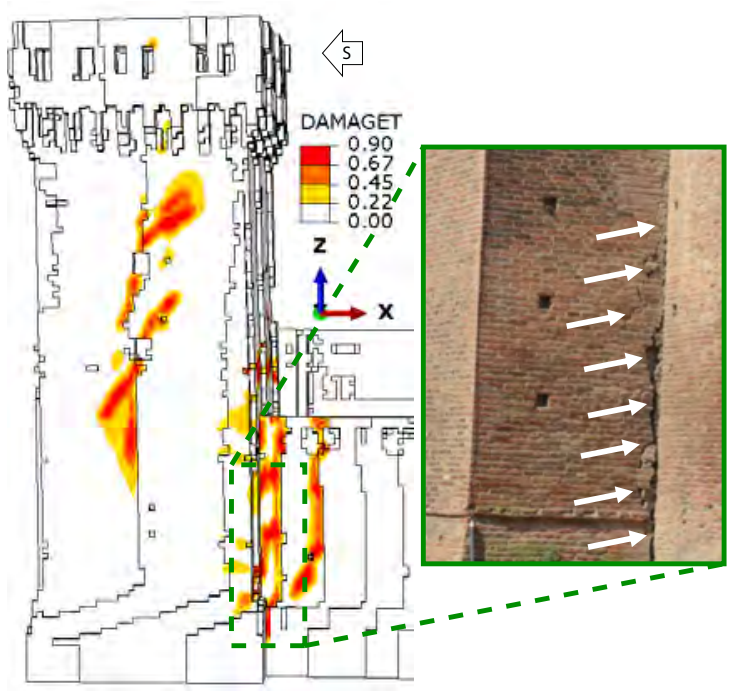

(a) East front

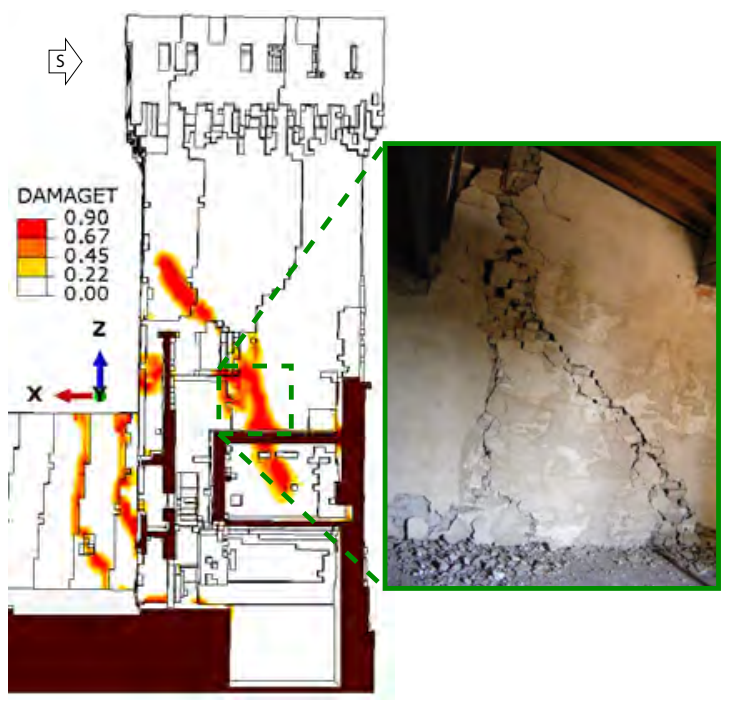

(b) West front

Figure 27: Pushover analyses with horizontal South directed force. Comparison between damage contour plots and the crack pattern. 


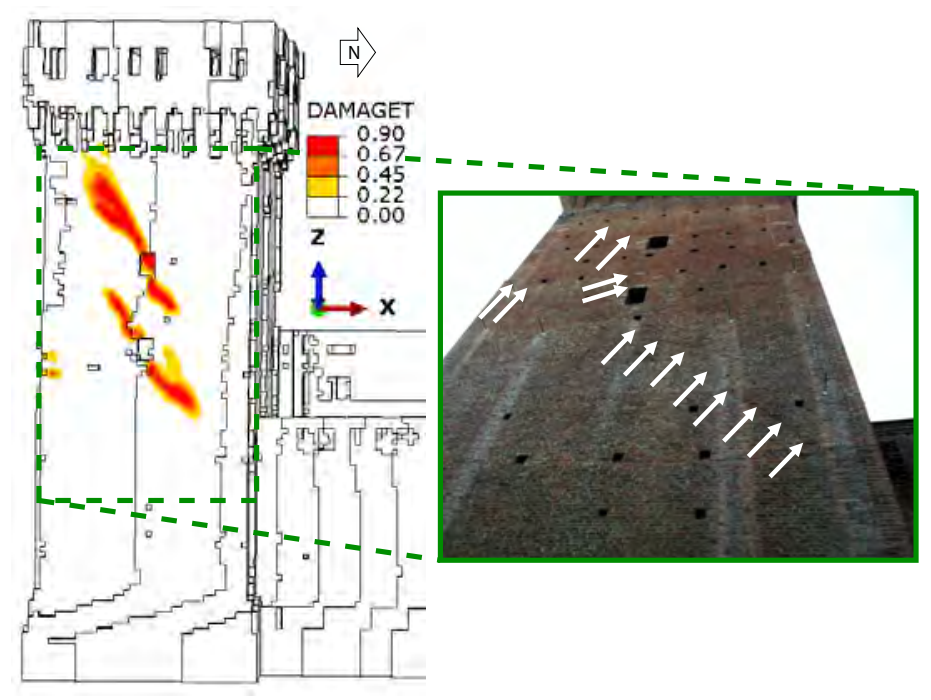

(a) East front

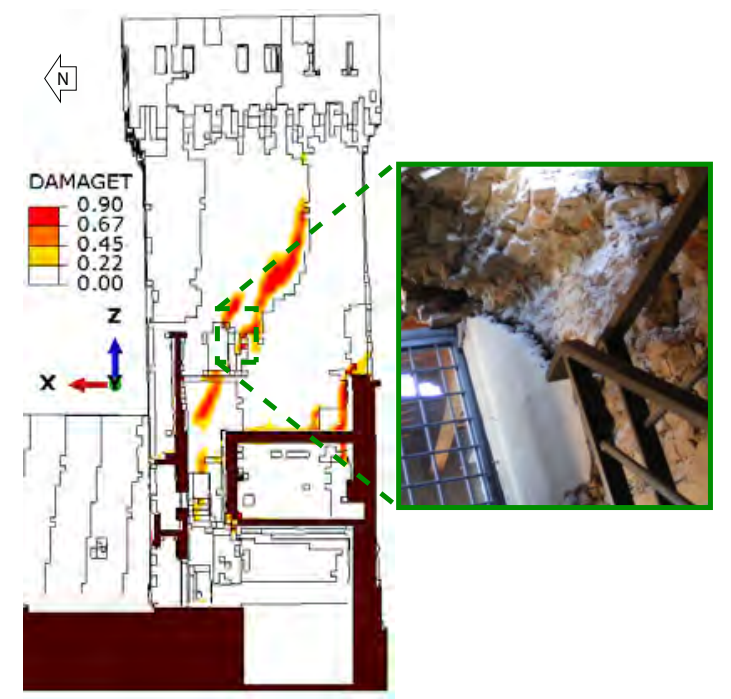

(b) West front

Figure 28: Pushover analyses with horizontal North directed force. Comparison between damage contour plots and the crack pattern. 


\section{Concluding Remarks}

An innovative modeling strategy for the numerical analysis of monumental historical buildings has been presented. The peculiar structural breakdown allows a fine semi-automatic generation of the structural domain starting from a TLS or photogrammetric survey. The complexity of the structure is surmountable by means of recursive simplifications of the geometrical domain. Once the domain has been reduced, the proposed meshing approach is able to always guarantee the generation of a "closed" mesh made by eight-node hexahedral elements. Therefore, an increase of the level of automation in the mesh generation process is attained and a large reduction in the required time in comparison to CAD-based modeling procedures is achieved. The validation of the strategy has been performed on the San Felice sul Panaro Fortress which embodies all the typical complexities of monumental historical buildings. The structural validation has been carried out on the whole fortress generated FE model through a comparison between the results of linear and nonlinear pushover analyses and the crack pattern present in the structure due to the Emilia earthquake (2012). Moreover, the vulnerability assessment of the main tower of the fortress has been performed on the generated mesh which leads to very accurate and easy-to-interpret findings. A good agreement between the numerical prediction and the crack pattern has been observed.

\section{Acknowledgments}

The authors would like to thank the municipality of San Felice sul Panaro (MO) for financial support and the unknown reviewers for the helpful suggestions to improve the quality of the paper. ABACUS (www.arcoabacus.it) is gratefully acknowledged for the supply of the fortress laser scanner survey. Furthermore, the authors would like to sincerely thank Ilenia Selvaggi, Alessandro Lambertini and Professor Gabriele Bitelli for contributions in the generation of slices from the points cloud of the fortress.

\section{References}

[1] Lagomarsino, S. On the vulnerability assessment of monumental buildings. Bulletin of Earthquake Engineering 2006, 4(4), 445-463.

[2] Formisano, A.; Florio, G.; Landolfo, R.; Mazzolani, F. M. Numerical calibration of an easy method for seismic behaviour assessment on large scale of masonry building aggregates. Advances in Engineering Software 2015, 80, 116-138.

[3] Cuadra, C.; Karkee, M. B.; Tokeshi, K. Earthquake risk to Inca's historical constructions in Machupicchu. Advances in Engineering Software 2008, 39(4), 336-345.

[4] Artioli, E.; Battaglia, R.; Tralli, A. Effects of May 2012 Emilia earthquake on industrial buildings of early ' 900 on the Po river line. Engineering Structures 2013, 56, 1220-1233.

[5] Macchi, G.; Ruggeri, M.; Eusebio, M.; Moncecchi, M. Structural assessment of the leaning tower of Pisa. In Proceedings of IABSE Symposium, 1993, IABSE, Zurich, Switzerland, 401-408.

[6] Chiarugi, A.; Fanelli, A.; Giuseppetti, G. Diagnosis and strengthening of the Brunelleschi Dome. In Proceedings of IABSE Symposium, 1993, IABSE, Zurich, Switzerland, 441-448.

[7] Croci, G. The Colosseum: safety evaluation and preliminary criteria of intervention. In Proceeding of Structural Analysis of Historical Constructions, 1995, Barcelona.

[8] Roca, P.; Cervera, M.; Gariup, G.; Pelá, L. Structural analysis of masonry historical construction. Classical and advanced approaches. Archives of Computational Methods in Engineering 2010, 17(3), 299-325. 
[9] Betti, M.; Orlando, M.; Vignoli, A. Static behaviour of an Italian Medieval Castle: Damage assessment by numerical modelling. Computers $\mathcal{E}$ Structures 2011, 89(21), 1956-1970.

[10] Cennamo, C.; Chiaia, B. M.; D’Angelo, S.; Ferretti, D. Seismic Assessment and Rehabilitation of a Historical Theater Based on a Macro-Element Strategy. International Journal of Architectural Heritage 2011, 5(3), 264295.

[11] Bartoli, G.; Betti, M.; Borri, C. Numerical Modeling of the Structural Behavior of Brunelleschi's Dome of Santa Maria del Fiore. International Journal of Architectural Heritage 2015, 9(4), 408-429.

[12] Blasi, C.; Coïsson, E.; Iori, I. The fractures of the French Panthéon: Survey and structural analysis. Engineering Fracture Mechanics 2008, 75(3-4), 379-388.

[13] Peña, F.; Lourenço, P.B.; Mendes, N.; Oliveira, D.V. Numerical models for the seismic assessment of an old masonry tower. Engineering Structures 2010, 32(5), 1466-78.

[14] Minghini, F.; Milani, G.; Tralli, A. Seismic risk assessment of a 50m high masonry chimney using advanced analysis techniques. Engineering Structures 2014, 69, 255-270.

[15] Minghini, F.; Bertolesi, E.; Del Grosso, A.; Milani, G.; Tralli, A. Modal pushover and response history analyses of a masonry chimney before and after shortening. Engineering Structures 2016, 110, 307-324.

[16] Maeda, T.; Sugiura, Y.; Hirai, T. FEM modeling of the towers in Bayon temple in Cambodia based on microtremor measurements. Advances in Engineering Software 2008, 39(4), 346-355.

[17] Milani, G.; Casolo, S.; Naliato, A.; Tralli, A. Seismic Assessment of a Medieval Masonry Tower in Northern Italy by Limit, Nonlinear Static, and Full Dynamic Analyses. International Journal of Architectural Heritage 2012, 6(5), 489-524.

[18] Acito, M.; Bocciarelli, M.; Chesi, C.; Milani, G. Collapse of the clock tower in Finale Emilia after the may 2012 Emilia Romagna earthquake sequence: Numerical insight. Engineering Structures 2014, 72, 70-91.

[19] Martínez, J.; Soria-Medina, A.; Arias, P.; Buffara-Antunes, A. F. Automatic processing of Terrestrial Laser Scanning data of building façades. Automation in Construction 2012, 22, 298-305.

[20] Stavroulaki, M.E.; Riveiro, B.; Drosopoulos, G.A.; Solla, M.; Koutsianitis, P.; Stavroulakis, G.E. Modelling and strength evaluation of masonry bridges using terrestrial photogrammetry and finite elements. Advances in Engineering Software 2016, Available online 13 January 2016, ISSN 0965-9978.

[21] Ordóñez, C.; Martínez, J.; Arias, P.; Armesto, J. Measuring building façades with a low-cost close-range photogrammetry system. Automation in Construction 2010, 19(6), 742-749.

[22] Styliadis, A. D. Digital documentation of historical buildings with 3-d modeling functionality. Automation in Construction 2007, 16(4), 498-510.

[23] Riveiro, B.; Solla, M.; de Arteaga, I.; Arias, P.; Morer, P. A novel approach to evaluate masonry arch stability on the basis of limit analysis theory and non-destructive geometric characterization. Automation in Construction 2013, 31, 140-148.

[24] Solla, M.; Lorenzo, H.; Novo, A.; Caamaño, J. C. Structural analysis of the Roman Bibei bridge (Spain) based on GPR data and numerical modelling. Automation in Construction 2012, 22, 334-339.

[25] Milani, G.; Esquivel, Y. W.; Lourenço, P. B.; Riveiro, B.; Oliveira, D. V. Characterization of the response of quasi-periodic masonry: Geometrical investigation, homogenization and application to the Guimarães castle, Portugal. Engineering Structures 2013, 56, 621-641.

[26] Saloustros, S.; Pelá, L.; Roca, P.; Portal, J. Numerical analysis of structural damage in the church of the Poblet Monastery. Engineering Failure Analysis 2015, 48, 41-61.

[27] Guarnieri, A.; Pirotti, F.; Pontin, M.; Vettore, A. Combined three-dimensional surveying techniques for structural analysis applications. In Proceedings of the Third IAG, 12th FIG symposium, 2006, Baden, Switzerland.

[28] Guarnieri, A.; Milan, N.; Vettore, A. Monitoring Of Complex Structure For Structural Control Using Terrestrial Laser Scanning (Tls) And Photogrammetry. International Journal of Architectural Heritage 2013, 7, 54-67.

[29] Lubowiecka, I.; Armesto, J.; Arias, P.; Lorenzo, H. Historic bridge modelling using laser scanning, ground penetrating radar and finite element methods in the context of structural dynamics. Engineering Structures 2009, 31, 2667-2676.

[30] Truong-Hong, L.; Laefer, D. Octree-based, automatic building facade generation from LiDAR data. ComputerAided Design 2014, 53, 46-61.

[31] Truong-Hong, L.; Laefer, D. Validating Computational Models from Laser Scanning Data for Historic Facades. 
Journal of Testing and Evaluation 2013, 41, 481-496.

[32] Hinks, T.; Carr, H.; Truong-Hong, L.; et al. Point Cloud Data Conversion into Solid Models via Point-Based Voxelization. Journal of Surveying Engineering 2013, 139, 72-83.

[33] Sienz, J.; Szarvasy, I.; Hinton, E.; Andrade, M. L. Computational modelling of 3D objects by using fitting techniques and subsequent mesh generation. Computers $\mathcal{E}$ Structures 2000, 78(1-3), 397-413.

[34] Borri, A.; Grazini, A. Diagnostic analysis of the lesions and stability of Michelangelo's David. Journal of Cultural Heritage 2006, 7, 273-285.

[35] Castellazzi, G.; D’Altri, A.M.; Bitelli, G.; Selvaggi, I.; Lambertini, A. From Laser Scanning to Finite Element Analysis of Complex Buildings by Using a Semi-Automatic Procedure. Sensors 2015, 15, 18360-18380.

[36] Bitelli, G.; Castellazzi, G.; D’Altri, A.M.; de Miranda, S.; Lambertini, A.; Selvaggi, I. Automated voxel model from point clouds for structural analysis of cultural heritage. In Proceeding of XXIII ISPRS Congress 2016, July 12-19, 2016, Prague, Czech Republic.

[37] DPCM 9/2/2011. Linee guida per la valutazione e la riduzione del rischio sismico del patrimonio culturale con riferimento alle Norme tecniche delle costruzioni di cui al decreto del Ministero delle Infrastrutture e dei trasporti del 14 gennaio 2008 [Italian guidelines for the evaluation and reduction of the seismic risk of cultural heritage, with reference to the Italian norm of constructions].

[38] Jean, M. The non-smooth contact dynamics method. Computer Methods in Applied Mechanics and Engineering 1999, 177 (3-4), 235-257.

[39] Pandolfi, A.; Kane, C.; Marsden, J. E.; Ortiz, M. Time-discretized variational formulation of non-smooth frictional contact. International Journal for Numerical Methods in Engineering 2002, 53(8), 1801-1829.

[40] Uchida, T. K.; Sherman, M. A.; Delp, S. L. Making a meaningful impact: modelling simultaneous frictional collisions in spatial multibody systems. Proceedings of the Royal Society A: Mathematical, Physical and Engineering Sciences 2015, 471(20140859). doi:10.1098/rspa.2014.0859

[41] Coïsson, E.; Ferrari, L.; Ferretti, D.; Rozzi, M. Non-smooth Dynamic Analysis of Local Seismic Damage Mechanisms of the San Felice Fortress in Northern Italy. Procedia Engineering 2016, 161, 451-457.

[42] Castellazzi, G.; de Miranda, S.; Mazzotti, C. Finite Element Modelling Tuned on Experimental Testing for the Structural Health Assessment of an Ancient Masonry Arch Bridge. Mathematical Problems in Engineering 2012, 2012, doi:10.1155/2012/495019.

[43] Orlando, A. Estense Fortress at San Felice Sul Panaro: modelling and seismic assessment. Master Thesis, Univestity of Genoa, Genoa, July 22th, 2014.

[44] Ferrari, L.; Goldoni, G. Behind the sign. Inside and Outside the San Felice sul Panaro Fortress restoration work. Master Thesis, University of Parma, Parma, 2014.

[45] Scognamiglio, L.; Margheriti, L.; Mele, F.M.; Tinti, E.; Bono, A.; de Gori, P. The 2012 Pianura Padana Emiliana seismic sequence: locations, moment tensors and magnitudes. Annals of Geophysics 2012, 55, 4.

[46] Cattari, S.; Degli Abbati, S.; Ferretti, D.; Lagomarsino, S.; Ottonelli, D.; Tralli, A. Damage assessment of fortresses after the 2012 Emilia earthquake (Italy). Bulletin of Earthquake Engineering 2014, 12, 2333-2365.

[47] Abaqus@. Theory manual, version 6.11; 2011.

[48] Castellazzi, G.; D’Altri, A.M.; de Miranda, S.; Ubertini, F.; Bitelli, G.; Lambertini, A.; Selvaggi, I.; Tralli, A. A mesh generation method for historical monumental buildings: an innovative approach. In Proceeding of the ECCOMAS Congress 2016 VII European Congress on Computational Methods in Applied Sciences and Engineering, 2016, Crete, Greece.

[49] DM 14/01/2008. Nuove norme tecniche per le costruzioni. Ministero delle Infrastrutture (GU n.29 04/02/2008), Rome, Italy [New technical norms on constructions].

[50] Circolare n 617 del 2 Febbraio 2009. Istruzioni per l'applicazione delle nuove norme tecniche per le costruzioni di cui al decreto ministeriale 14 Gennaio 2008 [Instructions for the application of the new technical norms on constructions].

[51] Ghandil, M.; Behnamfar, F. The near-field method for dynamic analysis of structures on soft soils including inelastic soil-structure interaction. Soil Dynamics and Earthquake Engineering 2015, 75, 1-17.

[52] Casarin, F. Structural assessment and seismic vulnerability analysis of a complex historical building. PhD Thesis, 2006, University of Trento, Trento, Italy.

[53] Meli, R.; Peña, F. On elastic models for evaluation of the seismic vulnerability of masonry churches. In Pro- 
ceedings of Structural analysis of historical constructions, 2004, Leiden, Netherlands.

[54] Castellazzi, G.; de Miranda, S.; Ubertini, F. Adaptivity based on the recovery by compatibility in patches. Finite Elements in Analysis and Design 2010, 46(5), 379-390.

[55] Castellazzi, G.; de Miranda, S.; Ubertini, F. Patch based stress recovery for plate structures. Computational Mechanics 2011, 47(4), 379-394.

[56] Valente, M.; Milani, G. Seismic assessment of historical masonry towers by means of simplified approaches and standard FEM. Construction and Building Materials 2016, 108, 74-104.

[57] Valente, M.; Milani, G. Non-linear dynamic and static analyses on eight historical masonry towers in the North-East of Italy. Engineering Structures 2016, 114, 241-270.

[58] Choudhury, T.; Milani, G.; Kaushik, H. B. Comprehensive numerical approaches for the design and safety assessment of masonry buildings retrofitted with steel bands in developing countries: The case of India. Construction and Building Materials 2015, 85, 227-246.

[59] Tiberti, S.; Acito, M.; Milani, G. Comprehensive FE numerical insight into Finale Emilia Castle behavior under 2012 Emilia Romagna seismic sequence: Damage causes and seismic vulnerability mitigation hypothesis. Engineering Structures 2016, 117, 397-421.

[60] Castellazzi, G.; D’Altri, A.M.; de Miranda, S.; Magagnini, S.; Tralli, A. On the seismic behavior of the main tower of San Felice sul Panaro (Italy) fortress. In Proceeding of ICCMSE 2016, March 17-20, 2016, Athens, Greece.

[61] Page, A.W. The biaxial compressive strength of brick masonry. In Proceeding of the Institution of Civil Engineers 1981, Part 2, 71, 893-906.

[62] Acito, M.; Chesi, C.; Milani, G.; Torri, S. Collapse analysis of the Clock and Fortified towers of Finale Emilia, Italy, after the 2012 Emilia Romagna seismic sequence: Lesson learned and reconstruction hypotheses. Construction and Building Materials 2016, 115 , 193-213.

[63] Borri, A.; Cangi, G.; De Maria, A. Caratterizzazione meccanica delle murature (anche alla luce del recente sisma in Emilia) e interpretazione delle prove sperimentali a taglio. In Proceedings of ANIDIS Congress, Associazione Nazionale Italiana Di Ingegneria Sismica, 2013, Padua, Italy [Mechanical characterization of masonry (considering also the recent Emilia earthquake) and interpretation of shear experimental tests].

[64] Cattari, S.; Resemini, S.; Lagomarsino, S.. Modelling of vaults as equivalent diaphragms in 3D seismic analysis of masonry buildings. In Proceedings of 6th international conference on structural analysis of historic construction, 2008, Bath, UK.

[65] Cattari, S.; Lagomarsino, S.; Resemini, S. Il ruolo delle volte nella risposta sismica degli edifici in muratura. In Archi e volte in zona sismica - Meccanica delle strutture voltate, 2012, Borri, A., Bussi, L., Eds. Doppiavoce, Naples, Italy [The role of vaults in the seismic response of masonry buildings].

[66] Fajfar, P. A nonlinear analysis method for performance-based seismic design. Earthquake Spectra 2000,16 (3), 573-592.

[67] Luzi, L.; Hailemikael, S.; Bindi, D.; Pacor, F.; Mele, F. ITACA (ITalian ACcelerometric Archive): A web portal for the dissemination of Italian strong motion data, Seismological Research Letters 2008, 79, 716-722.

[68] Lagomarsino, S.; Cattari, S. PERPETUATE guidelines for seismic performance-based assessment of cultural heritage masonry structures. Bulletin of Earthquake Engineering 2015, 13(1), 13-47. 